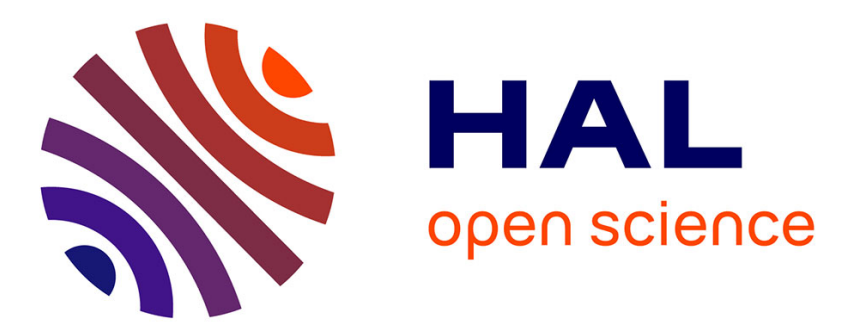

\title{
Bare soil HYdrological balance model "MHYSAN": calibration and validation using SAR moisture products and continuous thetaprobe network Measurements over bare agricultural soils (Tunisia)
}

Azza Gorrab, Vincent Simonneaux, Mehrez Zribi, S. Saadi, N. Baghdadi, Z. Lili-Chabaane, Pascal Fanise

\section{To cite this version:}

Azza Gorrab, Vincent Simonneaux, Mehrez Zribi, S. Saadi, N. Baghdadi, et al.. Bare soil HYdrological balance model "MHYSAN": calibration and validation using SAR moisture products and continuous thetaprobe network Measurements over bare agricultural soils (Tunisia). Journal of Arid Environments, 2017, 139, pp.11-25. 10.1016/j.jaridenv.2016.12.005 . hal-01580251

\section{HAL Id: hal-01580251 \\ https://hal.science/hal-01580251}

Submitted on 1 Sep 2017

HAL is a multi-disciplinary open access archive for the deposit and dissemination of scientific research documents, whether they are published or not. The documents may come from teaching and research institutions in France or abroad, or from public or private research centers.
L'archive ouverte pluridisciplinaire HAL, est destinée au dépôt et à la diffusion de documents scientifiques de niveau recherche, publiés ou non, émanant des établissements d'enseignement et de recherche français ou étrangers, des laboratoires publics ou privés. 
1 Bare Soil HYdrological Balance Model "MHYSAN": Calibration and

2 Validation Using SAR Moisture Products and Continuous Thetaprobe

3 Network Measurements over bare agricultural soils (Tunisia)

4 Azza Gorrab $^{1,2, *}$, Vincent Simonneaux ${ }^{2}$, Mehrez Zribi ${ }^{2}$, Sameh Saadi ${ }^{1,2}$, Nicolas Baghdadi ${ }^{3}$, 5 Zohra Lili-Chabaane ${ }^{1}$ and Pascal Fanise ${ }^{2}$

61 Institut National Agronomique de Tunisie/Université de Carthage,

743 Avenue Charles Nicolle, 1082 Tunis Mahrajène, Tunisie;

8 E-Mails: saadi_sameh@hotmail.fr ; zohra.lili.chabaane@gmail.com

92 Centre d'Etudes Spatiales de la Biosphère, 18 Av. Edouard Belin, BP 2801,

1031401 Toulouse Cedex 9, France;

E-Mails: vincent.simonneaux@ird.fr ; mehrez.zribi@ird.fr ; pascal.fanise@ird.fr

3 IRTEA-UMR TETIS Maison de la télédétection, Montpellier, 34093, France ;

E-Mails : nicolas.baghdadi@teledetection.fr

* Author to whom correspondence should be addressed; E-Mail: azzagorrab@gmail.com ; Tel.: +216-71-286-825; Fax: +216-71-750-254.

Abstract. The present study highlights the potential of multi-temporal X-band Synthetic Aperture Radar (SAR) moisture products to be used for the calibration of a model reproducing soil moisture (SM) variations. We propose the MHYSAN model (Modèle de bilan HYdrique des Sols Agricoles Nus) for simulating soil water balance of bare soils. This model was used to simulate surface evaporation fluxes and SM content at daily time scale over a semi-arid, bare agricultural site in Tunisia (North Africa). Two main approaches are considered in this study. Firstly, the MHYSAN model was successfully calibrated for seven sites using continuous thetaprobe measurements at two depths. Then the possibility to extrapolate local SM simulations at distant sites, based on soil texture similarity only, was tested. This extrapolation was assessed using SAR estimates and manual thetaprobe measurements of SM recorded at these distant sites. The results reveal a bias of approximately $0.63 \%$ and $3.04 \%$, and an RMSE equal to $6.11 \%$ and $4.5 \%$, for the SAR volumetric SM and manual thetaprobe measurements, respectively. In a second approach, the MHYSAN model was calibrated using seven very highresolution SAR (TerraSAR-X) SM outputs ranging over only two months. The simulated SM were validated using continuous thetaprobe measurements during 15 months. Although the SM was measured 
on only seven different dates for the purposes of calibration, satisfactory results were obtained as a result of the wide range of SM values recorded in these seven images. This led to good overall calibration of the soil parameters, thus demonstrating the considerable potential of Sentinel-1 images for daily soil moisture monitoring using simple models.

Keywords: Bare soil hydrological model, satellite soil moisture products, semi-arid area, continuous soil moisture measurements.

\section{Introduction}

The conservation of water and soil resources is one of the main missions for sustainable agricultural management. These natural resources are threatened by various types of degradation, such as water and wind erosion, floods, drought and deforestation, all of which impede agricultural development. In recent decades, the long periods of drought, especially in semi-arid regions, had a negative impact on available water resources. In addition, most of the intercepted water is lost through evaporation, or by drainage, deep percolation and subsurface runoff. Therefore, knowledge of water fluxes within the soilatmosphere system is a major issue for the improvement of water use efficiency. Many studies have been carried out to quantify these fluxes, and various tools have been developed to estimate the soilwater regime. These efforts can thus be expected to contribute to the sustainable management of natural resources (Er-Raki et al., 2007; Gowda et al., 2008; Simonneaux et al., 2008; Zhang et al., 2010; Li et al., 2009; Sutanto et al., 2012 and Saadi et al., 2015).

The amount of water stored in the soil is a crucial parameter, in situations where energy and mass fluxes at the land surface-atmosphere boundary need to be determined, and is of fundamental importance to many agricultural, hydrological, and meteorological processes (Koster et al., 2004; Seneviratne et al., 2010). Many soil water balance models have been developed, highlighting in particular the influence of surface soil moisture conditions on the hydrological response of a watershed (Famiglietti and Wood, 1994; Entekhabi and Rodriguez-lturbe, 1994 ; Zehe and Bloschl, 2004; Brocca et al., 2005 and 2008; Manfreda et al., 2005; Tramblay et al., 2012). Spatio-temporal soil moisture (SM) information is also of 

primary importance for the simulation of surface evaporation fluxes and vertical water circulation such as surface water displacement via capillarity, and underground percolation. It is important for the management of water resources, irrigation scheduling decisions, as well as the estimation of runoff and soil erosion potential (Chen and Hu, 2004; Koster et al., 2004; Pandey et al., 2010; Bezerra et al., 2013; Zhang et al., 2015). The spatial distribution of the soil's water content varies both vertically and horizontally, as a consequence of variations in precipitation and evaporation, and the influences of topography, soil texture, and vegetation.

As SM plays an important role in the hydrologic response, as well as land surface inputs to the atmosphere, large spatio-temporal databases of moisture observation data need to be maintained, and methodologies for the estimation of this key hydraulic property must be developed. This can be achieved through the use of SM monitoring networks, providing frequent temporal observations at a high spatial density. In situ station networks can be efficiently used as tools for the calibration of hydrological models, and their interest has been demonstrated in various studies using different remote sensing satellites and techniques (Wagner et al., 2008; Albergel et al., 2011; Gorrab et al., 2015b).

Considerable progress has been made in recent decades with the development of SM retrieval techniques, based on the analysis of remotely sensed radar data. The high spatial resolution and regular coverage provided by Imaging Synthetic Aperture Radar (SAR) sensors make these instruments a promising additional source of data for the measurement of seasonal and long-term variations in surface SM content, and could potentially improve hydrologic modeling applications (Baghdadi et al., 2008; Barrett et al., 2009). Several algorithms have been developed to retrieve soil moisture from radar data (Baghdadi et al., 2008; Zribi et al., 2011). In particular, the use of multi-temporal SAR acquisitions allows SM to be effectively estimated, using a small number of assumptions, by analyzing changes in radar backscattering over time (Zribi et al., 2005; Pathe et al., 2009; Gorrab et al., 2015b).

Subsequently, the integration of SM SAR products into hydrological balance models would be of considerable interest, since it could provide scientists with the opportunity to improve hydrological forecasting. Many recent studies have shown that the SM retrieved from SAR data generally agrees 
very well with that predicted by hydrological models (Baghdadi et al., 2007; Doubková et al., 2012; Iacobellis et al., 2013; Santi et al., 2013; Pierdicca et al., 2014). Baghdadi et al., 2007, showed that the monitoring of SM from SAR images was possible in operational phase. In fact, they compared moistures simulated by the operational Météo-France ISBA soil-vegetation-atmosphere transfer model with radar SM estimates to validate its pertinence. This comparison has shown an acceptable difference between ISBA simulations and radar estimates. Pierdicca et al., 2014 compared SM values generated by a soil water balance model with multi-temporal retrievals from ERS-1 images acquired over central Italy. Very good results were obtained at the scale of the watershed, showing that the short three-day revisit periodicity of ERS/SAR data can be used to compute relatively accurate estimations of the temporal variations in SM.

SM remote sensing outputs can also be used for data assimilation and calibration in hydrological transfer models, in order to evaluate their reliability (Weisse et al., 2003; Aubert et al., 2003; Qui et al., 2009; Brocca et al., 2010 and 2012; Draper et al., 2011; Renzullo et al., 2014; Massari et al., 2015; Lievens et al., 2015; López López et al., 2016). For example, Aubert et al., 2003, integrated remotely sensed SM data into their hydrological model, to improve the accuracy of their hydrological forecasts. Their methodology involved the implementation of a sequential assimilation procedure, allowing stepby-step control of the model's successive outputs, thereby avoiding any divergence with respect to the remotely sensed SM data. In a study published by (Brocca et al., 2010), a SM product derived from the Advanced SCATterometer (ASCAT) sensor was introduced into a rainfall-runoff model (MISDc) and applied to many sub-catchments of the Upper Tiber River in central Italy. The results reveal that even with a coarse spatial resolution, remote sensing data can considerably improve the accuracy of runoff predictions.

The growing availability of remote sensing SAR SM products, combined with the relatively large number of parameters involved in soil water processes, means that moisture satellite data can now be used for the calibration of distributed SM models. However, relatively few published studies have dealt with the calibration of hydrological models using SAR SM products (François et al., 2003, Pauwels et 
al., 2002; Matgen et al., 2006; Montanari et al., 2009). In this context, the present study focuses mainly on the effectiveness of high-resolution TerraSAR-X SM products to be used as calibration data in a hydrological model. We propose a new, simple soil hydrological model called MHYSAN ("Modelisation de Bilan HYdrique des Sols Agricoles Nus" in French, or "Water balance model for bare agricultural soils") which was used to compute surface evaporation and water balance in central Tunisia, thereby simulating soil moisture time series. Modeling bare soil behavior should be considered as a first step toward agricultural soil moisture monitoring, but is all the more as bare soils represent the majority of surface in our study area, like in most semi-arid areas. Our paper is organized in five sections. The following section presents the database and ground station measurements used in this study. Then, section 3 explains the functioning of the MHYSAN model and the calibration and validation method. The results of the calibration and validation processes are presented and discussed in Section 4, and then our conclusions and perspectives are provided in section 5.

\section{Database description}

\subsection{Study Area Description}

The experimental site is situated on the Kairouan plain $\left(9^{\circ} 30^{\prime} \mathrm{E}\right.$ to $10^{\circ} 15^{\prime} \mathrm{E}, 35^{\circ} \mathrm{N}$ to $\left.35^{\circ} 45^{\prime} \mathrm{N}\right)$, a semiarid region in central Tunisia (see Fig. 1) with an area of more than $3000 \mathrm{~km}^{2}$. In this region, the annual rainfall records are of approximately $300 \mathrm{~mm} /$ year, with the two rainiest months being October and March and the mean daily temperature is about $19.2^{\circ} \mathrm{C}$. The mean annual reference evapotranspiration estimated using the Penman-Monteith method is equal to $1600 \mathrm{~mm}$ (Zribi et al., 2011). Water management in the Merguellil basin is characteristic of semi-arid regions, with an upstream sub-basin collecting surface and subsurface flows to the El Haouareb dam, and a downstream plain supporting irrigated agriculture. Agriculture consumes more than $80 \%$ of the water extracted from the Kairouan aquifer. 


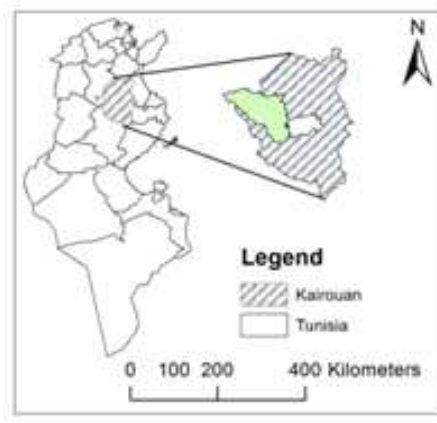

$9^{\circ} 0^{\prime} 0^{\circ}$

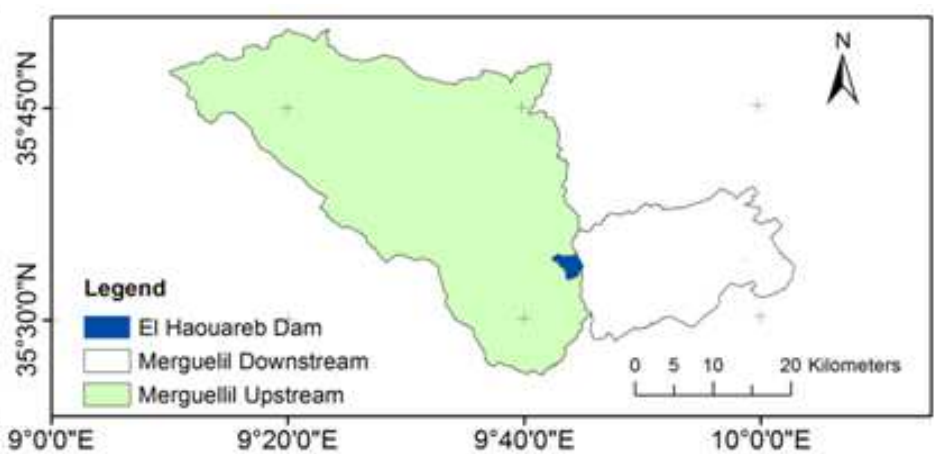

Figure 1: Localization of the study site.

\subsection{Ground and remote sensing database}

\subsubsection{Continuous in situ SM and meteorological data}

Ground-based SM measurements were obtained from a Continuous Soil Moisture Network (CSMN) which has been operated over the studied area since 2009. The CSMN network includes the following seven stations: Bouhajla, Hmidate, Sidi Heni, Chebika, Barrouta, Barrage and P12, as shown in Fig. 2. SM measurements were made with permanently installed Theta-Probe ML2X instruments, aligned horizontally at depths of 5 and $40 \mathrm{~cm}$. For each continuous probe, SM values were recorded at $4 \mathrm{~h}$ intervals and expressed in volumetric units $\left(\mathrm{m}^{3} / \mathrm{m}^{3}\right)$. Thetaprobe calibrations were performed during the commissioning phase through the use of several different gravimetric measurements (Amri et al., 2012). Table 1 provides the geographic coordinates and soil characteristics of each station, in terms of their bulk density and soil texture classes.

Table 1. Geographic coordinates and physical soil properties of the seven continuous thetaprobe stations (da: bulk density)

\begin{tabular}{|l|c|c|c|c|c|c|c|c|}
\hline Name & Lat(DD) & Long(DD) & da $_{5 \mathrm{~cm}}$ & $\mathbf{d a}_{40 \mathrm{~cm}}$ & \% Sand & \% Clay & \% Silt & Texture \\
\hline Bouhajla & $\mathrm{N} 35.3888$ & E10.0477 & 1.69 & 1.63 & 71.9 & 16.5 & 11.6 & sandy loam \\
\hline Sidi Heni & $\mathrm{N} 35.6630$ & E10.3404 & 1.35 & 1.6 & 48.5 & 28.1 & 23.4 & sandy clay loam \\
\hline Barrage & $\mathrm{N} 35.5702$ & $\mathrm{E} 9.7635$ & 1.60 & 1.69 & 58.1 & & 11.9 & sandy clay loam \\
\hline Barrouta & $\mathrm{N} 35.5778$ & $\mathrm{E} 10.0480$ & 1.56 & 1.59 & 65.4 & 27.7 & 6.9 & sandy clay loam \\
\hline Chebika & $\mathrm{N} 35.5504$ & $\mathrm{E} 9.9216$ & 1.32 & & 32 & 36.2 & 31.8 & clay loam \\
\hline
\end{tabular}




\begin{tabular}{|c|c|c|l|c|c|c|c|c|}
\hline P12 & N35.5563 & E9.8716 & 1.47 & & 69 & 18.5 & 13.5 & sandy loam \\
\hline Hmidate & N35.4757 & E9.8449 & 1.67 & & 81.1 & 12.7 & 6.2 & sandy loam \\
\hline
\end{tabular}

Half-hourly measurements of solar radiation, air temperature and humidity, wind speed and rainfall were recorded using two automated weather stations installed in the study area: Ben Salem and 148 Nasrallah (Fig. 2).

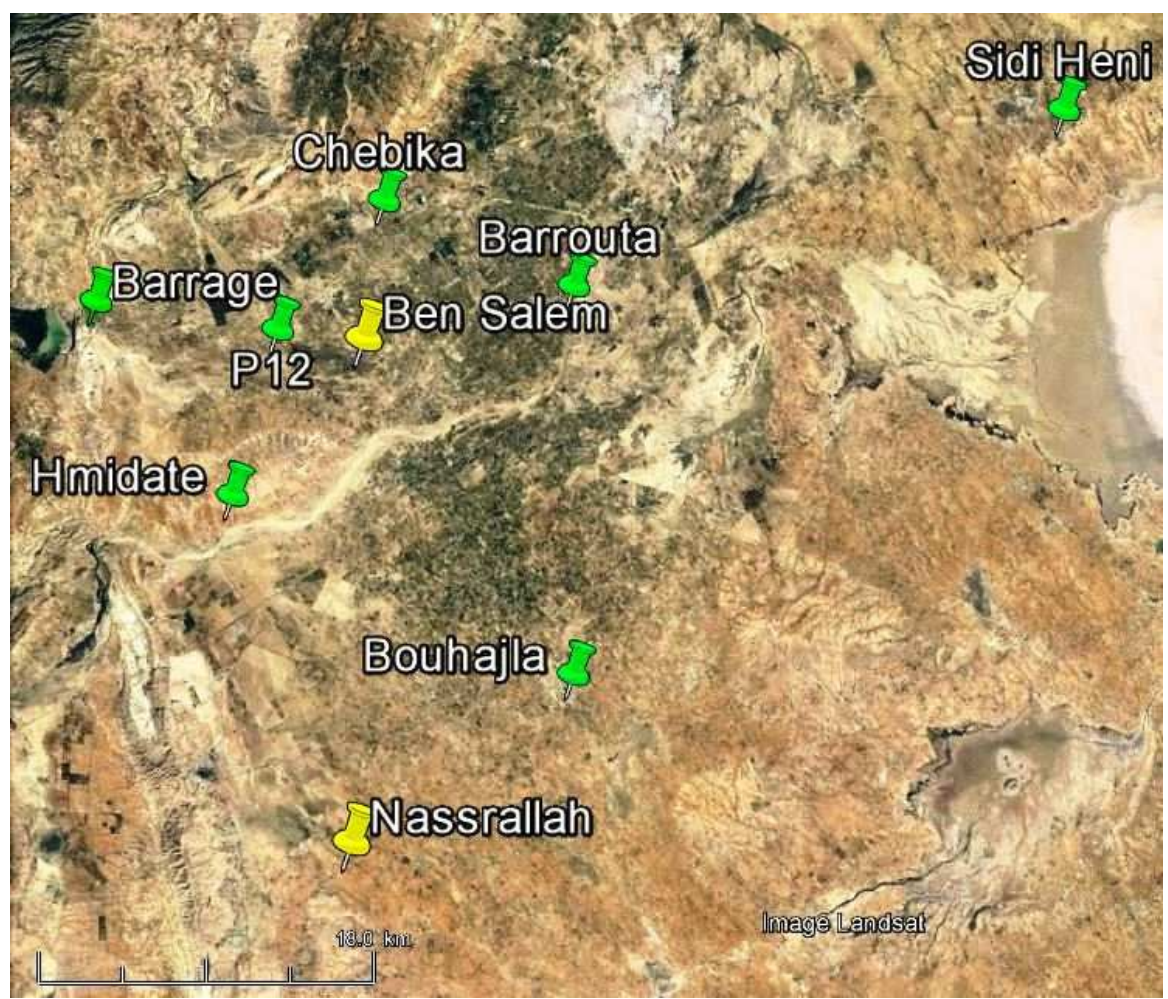

Figure 2: Locations of the continuous thetaprobe (green pins) and meteorological (yellow pins) stations (courtesy of Google Earth).

52 Fig. 3 shows the daily precipitation and reference evapotranspiration (ETo) time series obtained using 53 this meteorological data between January 2013 and August 2014 at the Ben Salem and Nasrallah 54 stations, respectively. In this study, we used the SM and meteorological measurements recorded during 55 the hydrological year of 2013-2014. 


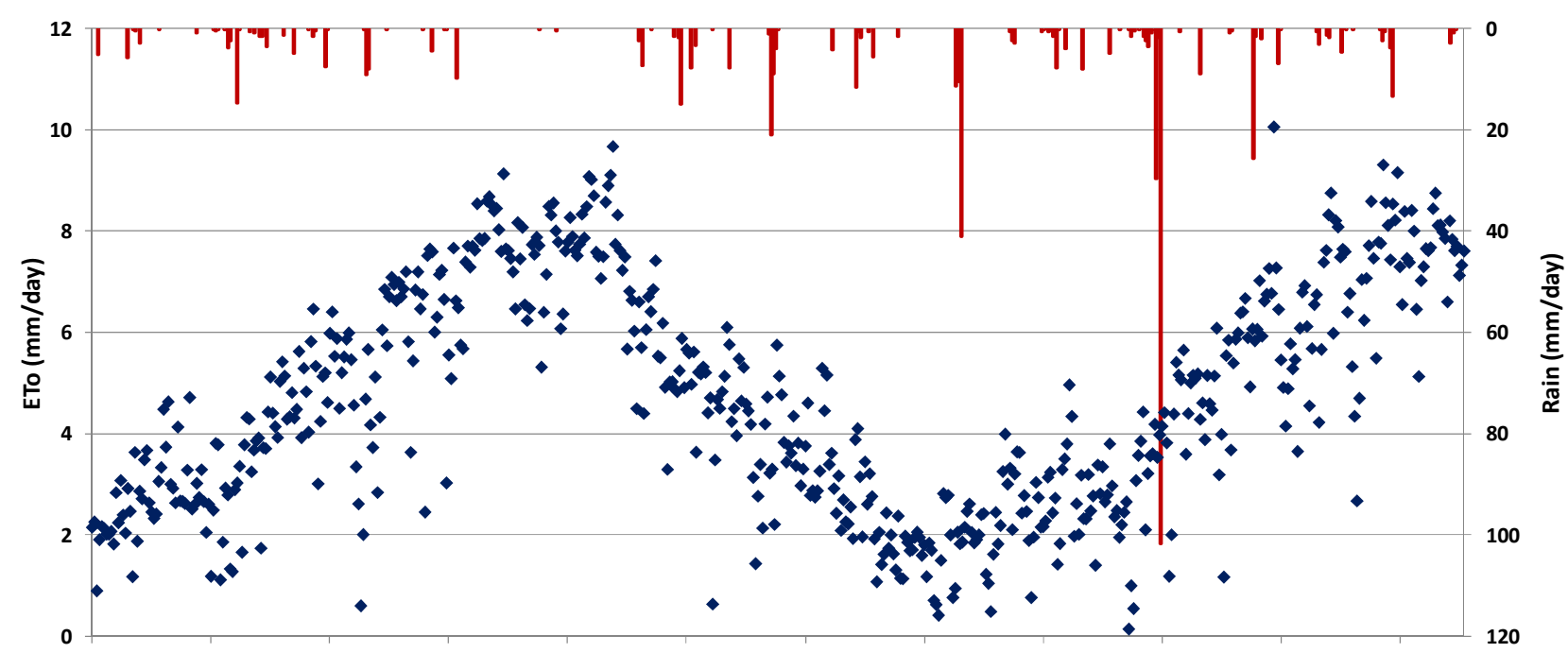

156 (a)

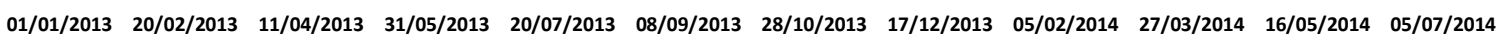

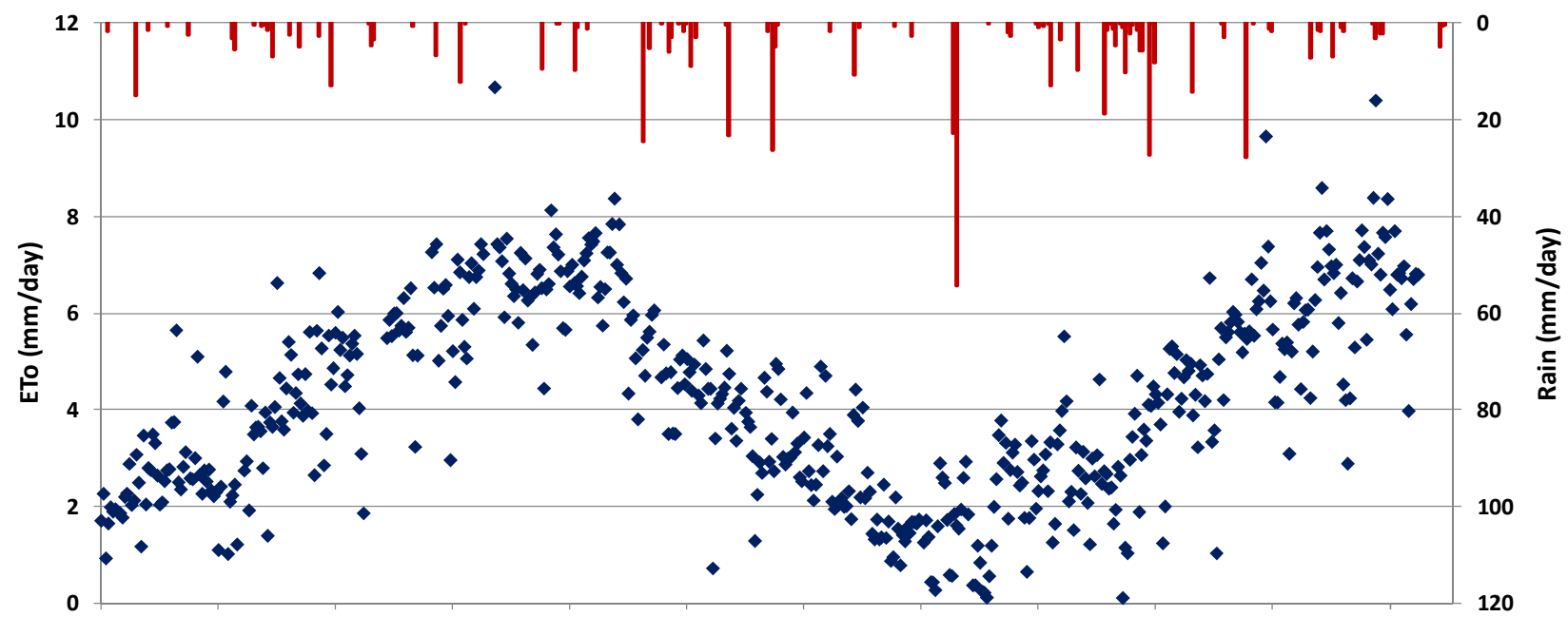

157 (b)

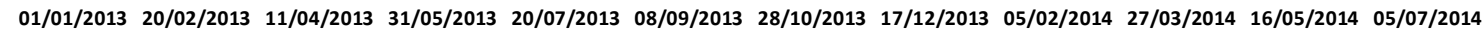

158 Figure 3: Mean daily rainfall (red bars at the top) and reference evapotranspiration "ETo" (blue points) recorded at two meteorological stations: (a) Nassrallah and (b) Ben Salem, for the hydrological year of

\subsubsection{Analysis of SM and rainfall time series}

162 The daily rainfall and SM variations for the 2013-2014 season were analyzed in order to check the 163 correlation between rainfall and soil moisture. Fig. 4 shows the example of the Chebika and Hmidate 164 probes. The rainfall gauges selected for each SM site were the closest to each of the continuous probe 
stations. The rainfall time series should be consistent with the temporal variations in SM recorded at the depths of $5 \mathrm{~cm}$ and $40 \mathrm{~cm}$.

From Fig. 4, it can be seen that SM variations in the shallow layer $(5 \mathrm{~cm})$ are very different to those observed in the deep layer $(40 \mathrm{~cm})$. The soil moisture content in both of these layers can be attributed mainly to the influence of the soil's texture and pore size distribution (Bezerra et al., 2013; Zhang et al., 2015; Shabou et al., 2015). We also note that the deeper the probes are, the smoother the recorded response. According to (Famiglietti et al., 1998; Amri et al., 2012), the amount of water stored in the first centimeter of top soil increases rapidly in the presence rainfall, and can decrease significantly within a few hours, due to atmospheric influences (evaporation ...). This is the reason for which, as shown in Fig. 4, the SM estimated at $40 \mathrm{~cm}$ is affected by considerably small variations than those measured at the surface $(5 \mathrm{~cm})$. A large water content in the deep soil layers maintains an upward vertical SM gradient, thereby contributing to the SM and evaporation observed in the shallow surface layers (Chen and $\mathrm{Hu}, 2004)$.

8 Overall, the precipitation inputs are quite well correlated with the observed SM variations, in particular 9 the surface $\mathrm{SM}\left(\theta_{5 \mathrm{~cm}}\right)$. For the 2013-2014 period, small discrepancies are occasionally observed between $8 \mathrm{SM}$ and precipitation, since rainfall events are not always accompanied by an increase in SM, and some 81 SM variations are not correlated with any rainfall event.

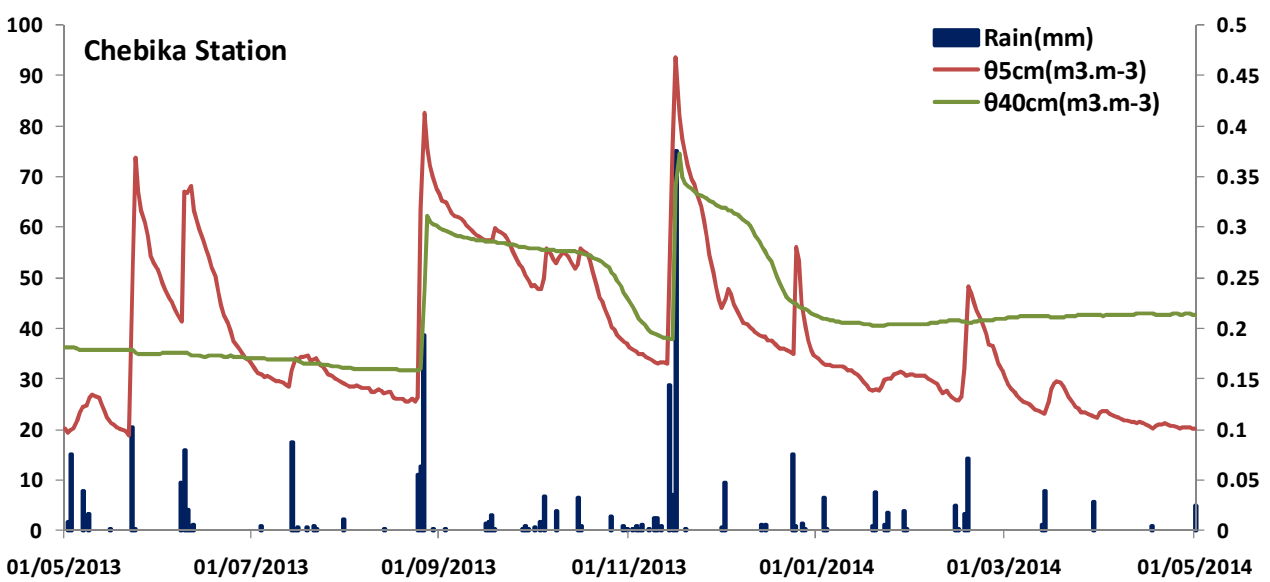
a) 

b)

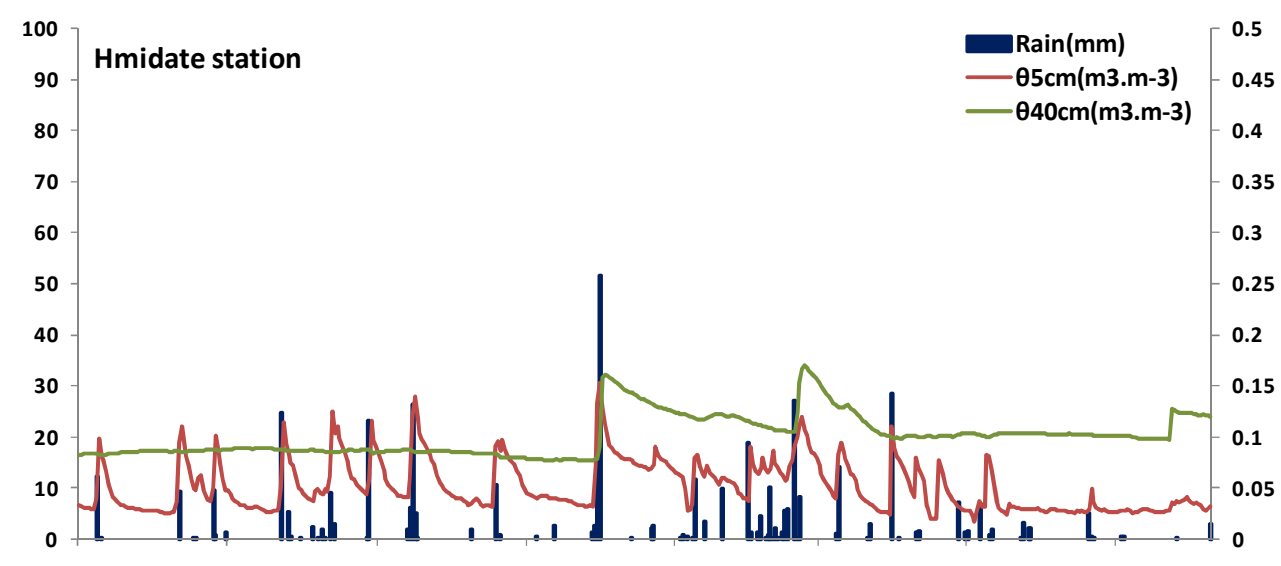

Figure 4: Correlation between daily precipitation data (blue bars) and SM time series recorded during the 2013-2014 season, using: a) the Chebika thetaprobe station b) the Hmidate thetaprobe station, at depths of $5 \mathrm{~cm}$ and $40 \mathrm{~cm}$.

\subsubsection{Soil moisture control plots}

SM measurements were collected from a set of 15 control plots on bare soil fields distributed over the study area, having different types of roughness ranging from smooth to ploughed surfaces (Fig.6). Ground campaigns were carried out from November 2013 to January 2014, simultaneously with SAR image acquisitions. The surface areas of these study fields ranged between 1.6 and 17 ha. Handheld thetaprobe measurements were made at a depth of $5 \mathrm{~cm}$, at approximately 20 points distributed over the entire surface area of each control plot, within a two-hour time frame between 3:40 p.m. and 5:40 p.m., coinciding with the time of each overhead satellite acquisition.

The manual thetaprobe measurements were calibrated using gravimetric measurements recorded during previous campaigns (Zribi et al., 2011). The ground-measured volumetric moisture "mv" values ranged between $4.7 \%$ to $31.6 \%$, for all manual thetaprobe measurements. For each control plot, three soil samples were collected, and the soil's texture was determined by measuring the percentages of sand, silt and clay particles in the laboratory (Gorrab et al., 2015a). These fractions were then classified according to the USDA textural triangle (Fig. 5). In our control plots, the observed variability of the soil's 
202 influence on its water retention capacity.

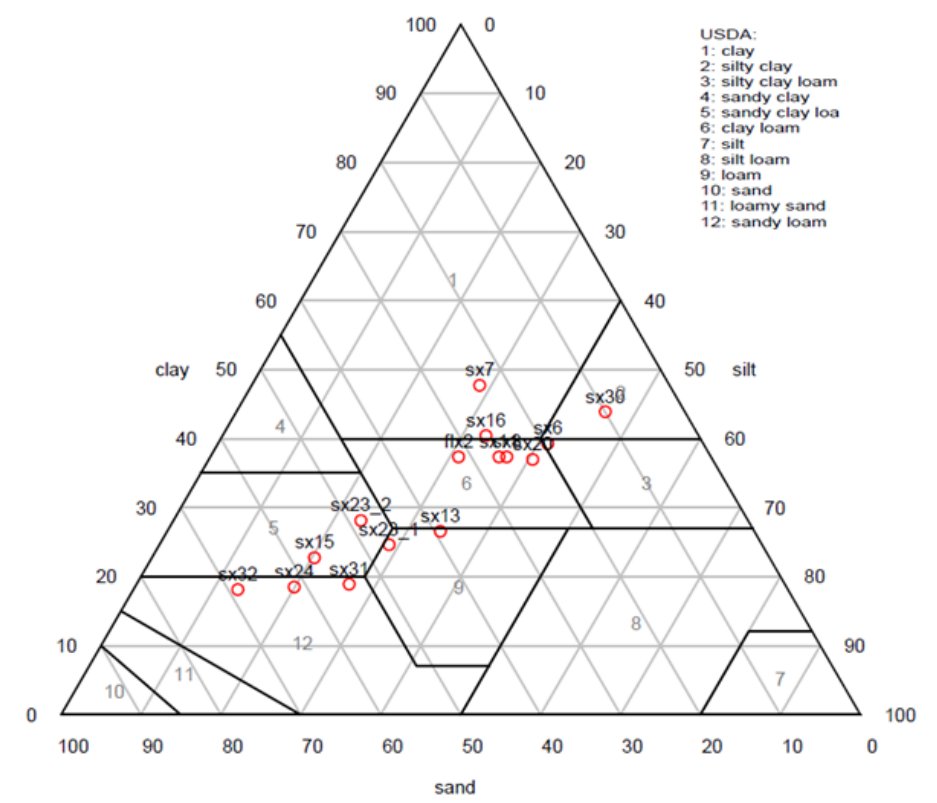

215 signals were computed for each control plot. 
216 The SM maps were produced using the multi-temporal TerraSAR-X data acquired at high spatial 217 resolution scale. For the estimation of bare surface SM, we propose an algorithm based on an empirical 218 change detection approach combining TerraSAR-X images with ground CSMN measurements. It is 219 important to note that we used only three continuous Thetaprobe stations from the CSMN, to calibrate 220 the SAR moisture products. In the following, we note these stations as $\left(\mathrm{CSMN}_{3}\right)$, as shown in Fig.6.

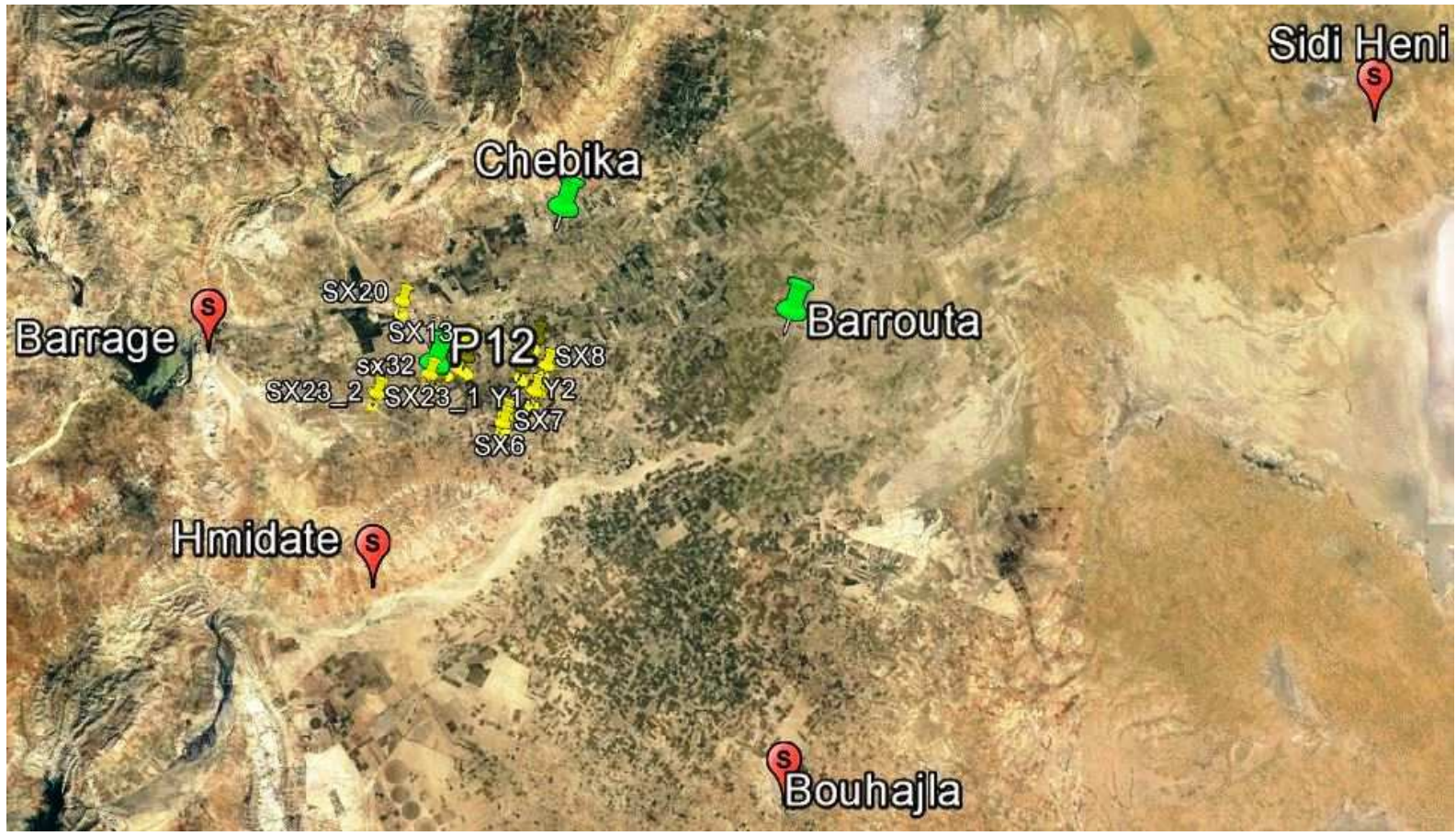

Figure 6. Location of the control plots (yellow pins) and the $\mathrm{CSMN}_{3}$ (green pins).

The methodology adopted in this study to estimate the spatial variability of SM is described in (Gorrab et al., 2015b). Our analysis is based on the seven radar images acquired over the study site.

The proposed approach takes advantage of the approximately linear dependence (in decibels) of radar backscattering signals on soil moisture. This linear relationship is modeled as:

$$
\sigma_{d B}^{0}=S_{0} m v+f(R)
$$



where $S_{0}$ is the radar signal's sensitivity to soil moisture $(\mathrm{mv})$, and $f(R)$ is a function of the roughness $R$. 229 The change in soil moisture $\Delta \mathrm{m}_{\mathrm{v}}$ between two successive TerraSAR-X image acquisitions (11 day 230 period in the case of the present study), can be expressed as:

$$
\Delta m_{v}=\frac{\Delta \sigma^{\circ}-\Delta f(R)}{S_{0}}
$$

where $\Delta \sigma^{\circ}$ is the radar signal difference, obtained by subtracting consecutive radar backscatter images acquired over a given area (i.e. the change in signal strength between two acquisition dates), and $\Delta f(R)$ is the difference in radar signal resulting from roughness contributions, between two successive radar images.

The proposed algorithms are validated by comparing the radar estimations with ground-truth measurements made in control plots, characterized by soil moistures ranging between dry and wet conditions. Since a small improvement in the soil moisture estimation accuracy is observed when the roughness variations are taken into account, the resulting soil moisture maps are computed for each date $\mathrm{d}_{\mathrm{t}}$ and each pixel $(\mathrm{i}, \mathrm{j})$, as:

$$
m_{v}\left(i, j, d_{t}\right)=\Delta m_{v}\left(i, j, d_{t}, d_{t-1}\right)+m_{v}\left(i, j, d_{t-1}\right)
$$

where $m_{v}\left(i, j, d_{t}\right)$ is the SM at pixel $(\mathrm{i}, \mathrm{j})$ and date $\mathrm{d}_{\mathrm{t}}, m_{v}\left(i, j, d_{t-1}\right)$ is the SM at pixel $(\mathrm{i}, \mathrm{j})$ and date $\mathrm{d}_{\mathrm{t}-1}$, and $\Delta m_{v}\left(i, j, d_{t}, d_{t-1}\right)$ is the change in SM at pixel $(\mathrm{i}, \mathrm{j})$, between the dates $d_{t}, d_{t-1}$.

44 Fig. 7 shows three bare soil moisture maps computed using the above algorithm on three different dates:

$245 * 12 / 12 / 2013$ : was a dry date, and the spatial variations in soil moisture can be seen to be low.

$* 23 / 12 / 2013$ : was the wettest day (the recorded precipitation was approximately $38.6 \mathrm{~mm}$ ), and the spatial variations in soil moisture are relatively homogenous (dark blue)

*14/01/2014: was characterized by medium values of soil moisture and highly heterogeneous levels of soil moisture (dark blue to light).

250 The TerraSAR-X SM maps provided data representing the volumetric soil moisture content expressed 251 in volumetric percentage units (vol. \%). 

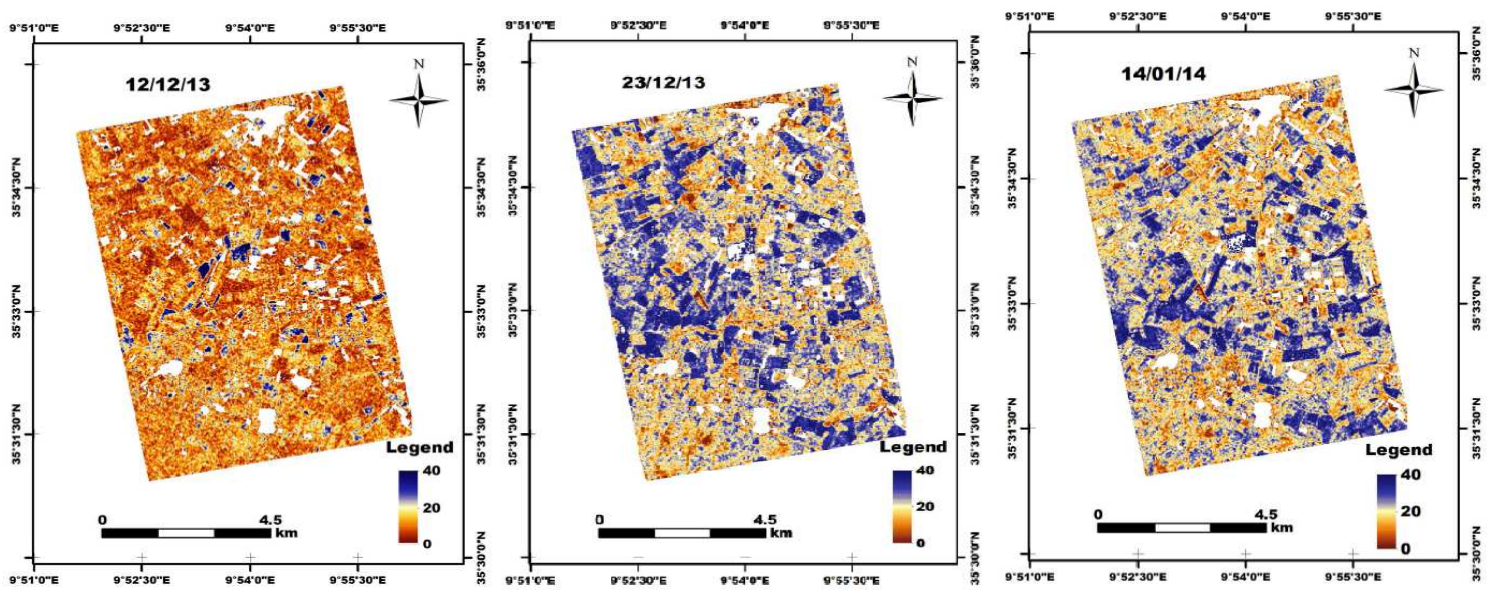

Figure 7: Three surface SM TerraSAR-X products.

\section{Bare soil hydrological balance estimation}

\section{3.1 MHYSAN model description}

256 The "MHYSAN" model simulates the soil water balance at 24-hour intervals, using daily precipitation 257 and meteorological data as inputs for the estimation of evaporation. The model considers a dual soil 258 layer structure: a surface layer from which moisture can evaporate, and a deep layer where water is 259 stored (fig.8). During rainfall events, the gravity makes water successively fill the soils' compartments 260 from top to bottom. In this model, lateral circulation of water (overland and subsurface runoff) is 261 assumed to be negligible. When all compartments are full, any excess water flows out of the system by 262 means of deep drainage (Simonneaux et al., 2009, Saadi et al., 2015). 

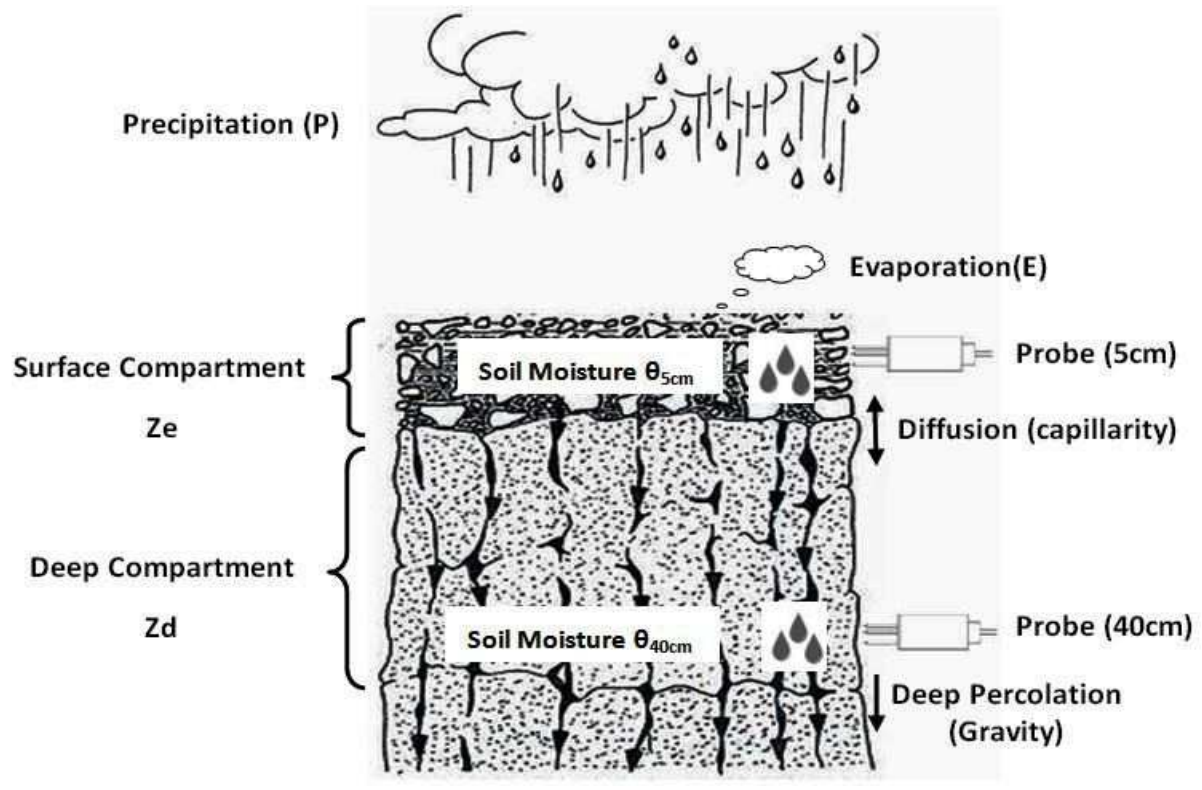

Figure 8: Schematic representation of the conceptual bare soil hydrological model "MHYSAN".

$265 \mathbf{Z}_{\mathbf{e}}[\mathrm{mm}]$ is the height of the evaporative layer. Below this surface layer, a deep layer of height $\mathbf{Z}_{\mathbf{d}}[\mathrm{mm}]$ 266 is modeled. TEW is the water column [mm] representing the difference between the moisture content at 267 field capacity and the residual water content that cannot be evaporated from the soil, and is described by 268 the following expression Eq. (1):

$$
T E W=(\theta f c-\theta r e s) * Z e,
$$

270 The evaporative capacity of the deep compartment (TDW) is computed in a similar manner to the TEW, 271 using the following expression Eq. (2):

$$
T D W=(\theta f c-\theta r e s) * Z d
$$

273 Capillary processes are also modeled in MHYSAN, either upwards or downwards, between the 274 evaporative layer and the deep compartment, on the basis of their relative water contents. In particular, 275 this allows evaporation to continue long after a rainfall event, since the deeper layers can sustain low 276 evaporation fluxes at the surface. The daily amount of water diffusing between the two layers, Dif ed $_{\text {, }}$ is 277 computed following Eq. (3): 


$$
D i f_{e d}=\operatorname{cdif} *\left(\frac{\frac{\left(\mathrm{TDW}-\mathrm{D}_{\mathrm{d}, \mathrm{i}}\right)}{\mathrm{Zd}}-\frac{\left(\mathrm{TEW}-\mathrm{D}_{\mathrm{e}, \mathrm{i}}\right)}{\mathrm{Ze}}}{\theta \mathrm{fc}}\right),
$$

279 where $D_{e, i}$ and $D_{d, i}$ represent the depletion of water in the evaporation and deep layers for day i (i.e. the 280 volume of voids as compared to soil at field capacity), and cdif is the diffusion coefficient [mm day $^{-1}$ ].

281 The MHYSAN model balances the soil's daily water budget by ensuring that water inputs and outputs 282 are conserved, in accordance with the following expression Eq. (4):

$$
E_{i}+D P_{i}+\Delta S W_{i}=P_{i}
$$

284 with:

$285 \mathrm{E}_{\mathrm{i}} \quad$ Evaporation

$286 \mathrm{DP}_{\mathrm{i}} \quad$ Deep Percolation (drainage)

$287 \Delta \mathrm{SW}_{\mathrm{i}} \quad$ Variation of the soil's water content

$288 \mathrm{P}_{\mathrm{i}} \quad$ Precipitation

289 The evaporation $\left(E_{i}\right)$ from a bare soil surface is defined as the volume of water vapor removed from the 290 soil's surface and transferred to the atmosphere and is estimated using the FAO-56 formalism (Allen et 291 al., 1998) using equation 5:

$$
E_{i}=K_{e, i} * E T_{0}
$$

293 Where

294 ETo is the grass reference evapotranspiration ( $\mathrm{mm} /$ day). This term was computed using the expressions 295 proposed by Allen et al. (1998), where $K_{e, i}$ is the evaporation coefficient, related to the volume of 296 water in the surface layer, obtained with equation 6:

$$
K_{e, i}=\frac{\left(\mathrm{TEW}-\mathrm{D}_{\mathrm{e}, \mathrm{i}}\right)}{\left(\mathrm{TEW}-\mathrm{R}_{\mathrm{E}}\right)} \leq 1
$$

298 and $\mathrm{R}_{\mathrm{E}}$ is the coefficient of resistance to evaporation.

299 The depletion $\left(\mathbf{D}_{\mathbf{e}, \mathbf{i}}\right)$ is updated every day from the soil water balance as follows: 
301 If $\mathrm{D}_{\mathrm{e}, \mathrm{i}}<0$ then:

$$
\mathrm{D}_{\mathrm{e}, \mathrm{i}}=0
$$

Depletion in the deep layer $\left(\mathbf{D}_{\mathbf{d}, \mathbf{i}}\right)$ is computed as follows:

$$
\left\{\begin{array}{c}
D_{d, i}=D_{d, i-1}-D P_{d, i}+D i f_{e d} \\
0 \leq D_{d, i} \leq T D W
\end{array}\right.
$$

If $\mathrm{Dd}<0$, then:

$$
\mathrm{DP}_{\mathrm{d}, \mathrm{i}}=-\mathrm{D}_{\mathrm{d}, \mathrm{i}}
$$$$
\mathrm{D}_{\mathrm{d}, \mathrm{i}}=0
$$

where $\mathbf{D P}_{\mathbf{d}, \mathbf{i}}$ is the assumed value of deep percolation on day $\mathrm{i}[\mathrm{mm}]$.

310 The volumetric soil moisture contents $\theta\left[\mathrm{m}^{3} \mathrm{~m}^{-3}\right]$ at depths of 5 and $40 \mathrm{~cm}$ are determined by the 311 MHYSAN model from the following relationships:

$$
\theta_{5 c m}=\theta_{r e s}+\left(\theta_{f c}-\theta_{r e s}\right) *\left(T E W-D_{e, i}\right) / T E W,
$$

313 and

$$
\theta_{40 \mathrm{~cm}}=\theta_{\text {res }}+\left(\theta_{f c}-\theta_{\text {res }}\right) *\left(T D W-D_{d, i}\right) / T D W
$$

\section{$315 \quad 3.2$ Model calibration and validation}

We choose to calibrate some parameters of the MHYSAN as shown in Table 2. These parameters are related to the soil's hydraulic properties, and are specific to each type of soil, depending on the size

318 distribution and structure of its pore spaces. Some of the model parameters were fixed from ground 319 moisture profiles measured at depths of $5 \mathrm{~cm}$ and $40 \mathrm{~cm}$ (e.g. the initial soil moisture content H_Init and 320 the residual soil moisture content $\theta_{\text {res }}$ ). The other parameters were calibrated using the observed soil moisture data. We choose to fix $\theta_{\text {res }}$ but not $\theta_{\mathrm{fc}}$ because the water holding capacity is not related to 
absolute values of these parameters but only to their difference. The soil parameters retained after calibration of the MHYSAN model are summarized in Table 3.

The calibration involves maximizing the Nash-Sutcliffe efficiency computed between observed and modeled values of soil moisture, at depths of 5 and $40 \mathrm{~cm}$. This is written as:

$$
N A S H=\left[1-\frac{\sum_{i=1}^{n}\left(\theta_{i}^{o b s}-\theta_{i}^{s i m}\right)^{2}}{\sum_{i=1}^{n}\left(\theta_{i}^{o b s}-\bar{\theta}^{o b s}\right)^{2}}\right] * 100,
$$

where $\theta_{\mathrm{i}}{ }^{\text {obs }}$ is the observed value of soil moisture on day $\mathrm{i}, \theta_{\mathrm{i}}^{\text {sim }}$ is the modeled value of soil moisture on day $\mathrm{i}$, and $\overline{\theta^{o b s}}$ is the observed mean value of soil moisture over the entire period under consideration. The Nash efficiency varies between 100 and $-\infty$, with an efficiency of 100 indicating a perfect fit between the modeled outputs and observations. A negative Nash efficiency indicates that the mean value of the observed time series would have been a better predictor than the model. In the present study, the NASH efficiency coefficients were used for the calibration and validation of the MHYSAN model. The discrepancies observed between the SM observations and MHYSAN simulations are expressed also in the form of two statistical indices: root mean square error (RMSE) and bias.

Table 2. Model parameters used for the evaporation and moisture simulations

\begin{tabular}{|c|c|c|}
\hline Soil parameters & Description & Data Sources \\
\hline$\theta_{\mathrm{fc}}\left[\mathrm{m}^{3} \mathrm{~m}^{-3}\right]$ & $\begin{array}{l}\text { Volumetric water content at field } \\
\text { capacity }[0-1]\end{array}$ & $\begin{array}{c}\text { Derived from the MHYSAN } \\
\text { calibration }\end{array}$ \\
\hline$\theta_{\text {res }}\left[\mathrm{m}^{3} \mathrm{~m}^{-3}\right]$ & Residual moisture content $[0-1]$ & $\begin{array}{l}\text { Derived from ground moisture } \\
\text { profiles }\end{array}$ \\
\hline $\mathrm{R}_{\mathrm{E}}[\mathrm{mm}]$ & $\begin{array}{c}\text { Coefficient of resistance to } \\
\text { evaporation }\end{array}$ & $\begin{array}{c}\text { Derived from the MHYSAN } \\
\text { calibration }\end{array}$ \\
\hline $\operatorname{cdif}\left[\mathrm{mm} \cdot \mathrm{day}^{-1}\right]$ & $\begin{array}{l}\text { Diffusion coefficient for the } \\
\text { hydraulic gradients between the } \\
\text { deep and surface compartments }\end{array}$ & $\begin{array}{l}\text { Derived from the MHYSAN } \\
\text { calibration }\end{array}$ \\
\hline H_Init $\left[\mathrm{m}^{3} \mathrm{~m}^{-3}\right]$ & $\begin{array}{l}\text { Initial soil moisture content at } \\
\text { depths of } 5 \mathrm{~cm} \text { and } 40 \mathrm{~cm}\end{array}$ & $\begin{array}{l}\text { Derived from ground moisture } \\
\text { profiles }\end{array}$ \\
\hline $\mathrm{Ze}[\mathrm{mm}]$ & Height of the surface layer & $\begin{array}{c}\text { Derived from the MHYSAN } \\
\text { calibration }\end{array}$ \\
\hline $\mathrm{Zd}[\mathrm{mm}]$ & Height of the deep layer & Derived from the MHYSAN \\
\hline
\end{tabular}


In this work, SM data derived from either CSMN stations or SAR moisture products were used to calibrate the model and independent SM data were used to validate the model (Fig.9). In fact, two approaches were considered for calibration of the MHYSAN model. In the first approach, model calibration was carried out using the CSMN data. The purpose of this step was to assess the intrinsic ability of MHYSAN to simulate soil moisture. Then, we tested the possibility to spatially extrapolate the local MHYSAN SM simulations based on the texture similarity of distant sites, assuming meteorological forcing are the same. This extrapolation was assessed using punctual thetaprobe SM measurements and SAR SM estimates available for independent control plots.

SM observations

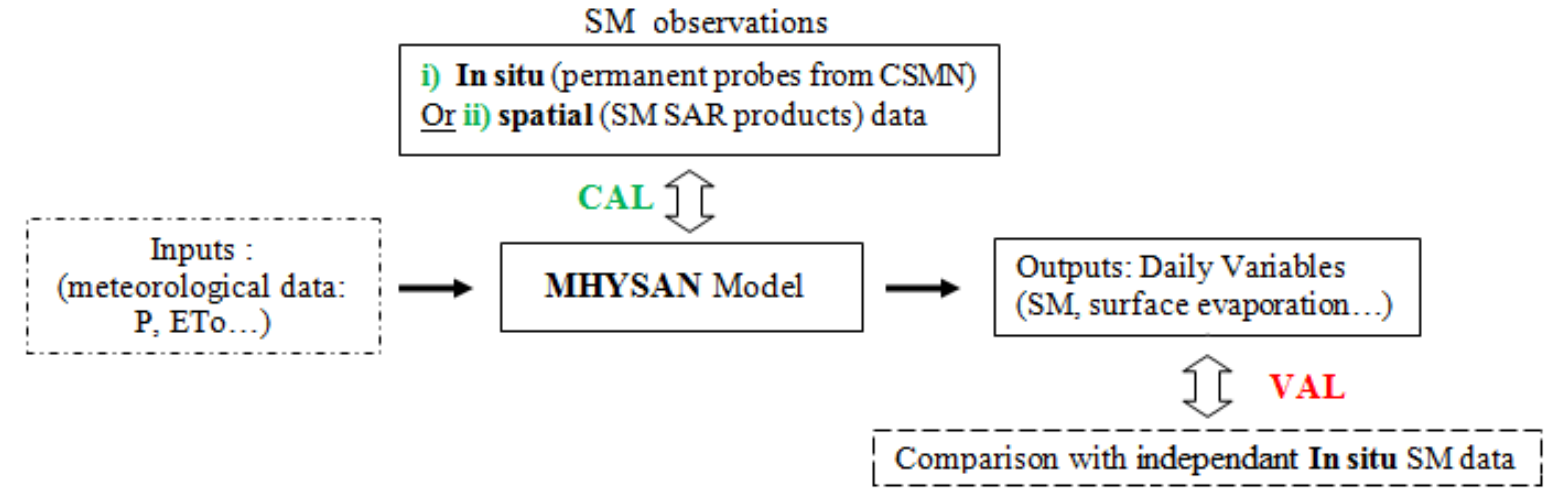

Figure 9: Use of soil moisture data (in situ continuous probes or radar images) in the MHYSAN model In the second approach, the objective was to test the use of remotely sensed data alone (SAR) to calibrate the model. Calibration was performed using the SM TerraSAR-X products retrieved on seven different dates ranging between November and January. The validation was achieved by comparing model predictions with measurements collected for the four CSMN sites (Bouhajla, Sidi Heni, Barrage and Hmidate) that were not used for SAR SM calculation. Because the knowledge of texture was necessary to derive SM from SAR data, it was calculated only for the control plots. The selection of the control plots for which SAR SM estimates will be used for MHYSAN calibration was achieved based on texture similarities between CSMN stations used for validation and the control plots. The similarity 
354 was based on the the euclidean distances between texture components, namely percentage of clay, silt 355 and sand.

\section{Results and Discussion}

\subsection{MHYSAN model calibration using SM measurements}

In the present step, the MHYSAN model was implemented for the seven continuous probe stations, in an attempt to reproduce the SM time series observed by each continuous thetaprobe at depths of 5 and $40 \mathrm{~cm}$. Fig. 10 provides a plot of the estimated values of the main water balance components, in particular soil moisture and evaporation time series, for three CSMN stations (2013-2014 period).

Table 3 lists the MHYSAN parameters which were established as described in the table 2 (section 3.2) and retained for each continuous thetaprobe station. The time-dependent agreement between the observed and simulated SM time series is characterized by the NASH efficiency coefficients at depths of $5 \mathrm{~cm}$ and 40 $\mathrm{cm}$. Following calibration, the NASH efficiency coefficients ranged between 81.2 and $52 \%$ for $\mathrm{NASH}_{5 \mathrm{~cm}}$ and between 76.3 and $11 \%$ for $\mathrm{NASH}_{40 \mathrm{~cm}}$. Overall, the results for the surface horizon at a depth of $5 \mathrm{~cm}\left(\theta_{5 \mathrm{~cm}}\right)$ are better than those corresponding to the layer located at a depth of $40 \mathrm{~cm}\left(\theta_{40 \mathrm{~cm}}\right)$. Discrepancies are occasionally observed for the period from 2013-2014, when the simulated MHYSAN SM responses are higher or lower than the SM continuous probes measurements. In addition, we note that the agreement between simulations and observations is not as good in the case of the Sidi Heni station. This can be explained by the poor representativity of the rainfall data considered for this station, which is more remote than the other stations (situated at approximately $39 \mathrm{~km}$ from the Ben Salem meteorological station). 
(a)

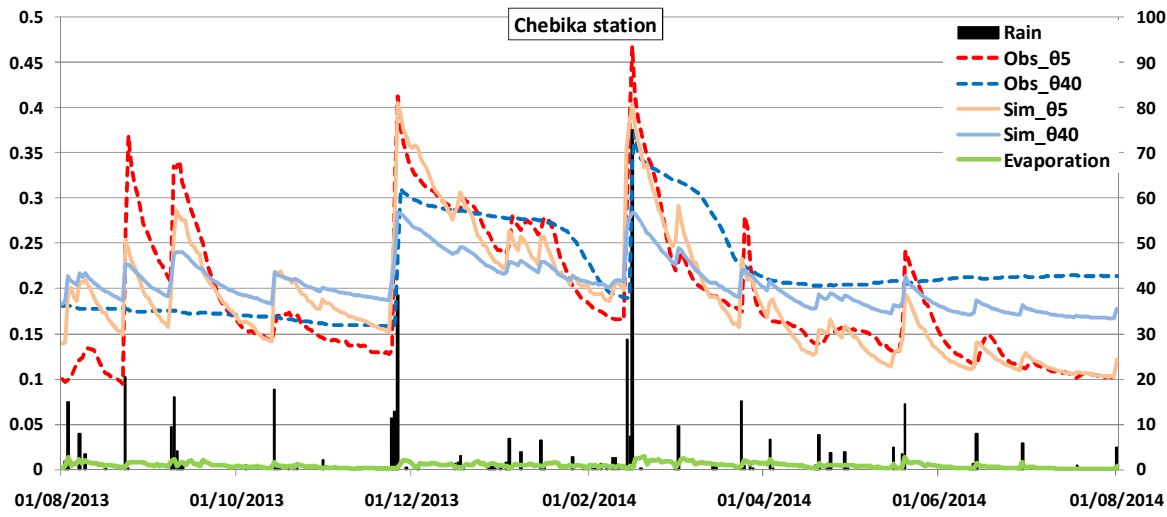

(b) 01/05/2013 16/06/2013 01/08/2013 16/09/2013 01/11/2013 17/12/2013 01/02/2014 19/03/2014 04/05/2014 19/06/2014 04/08/2014
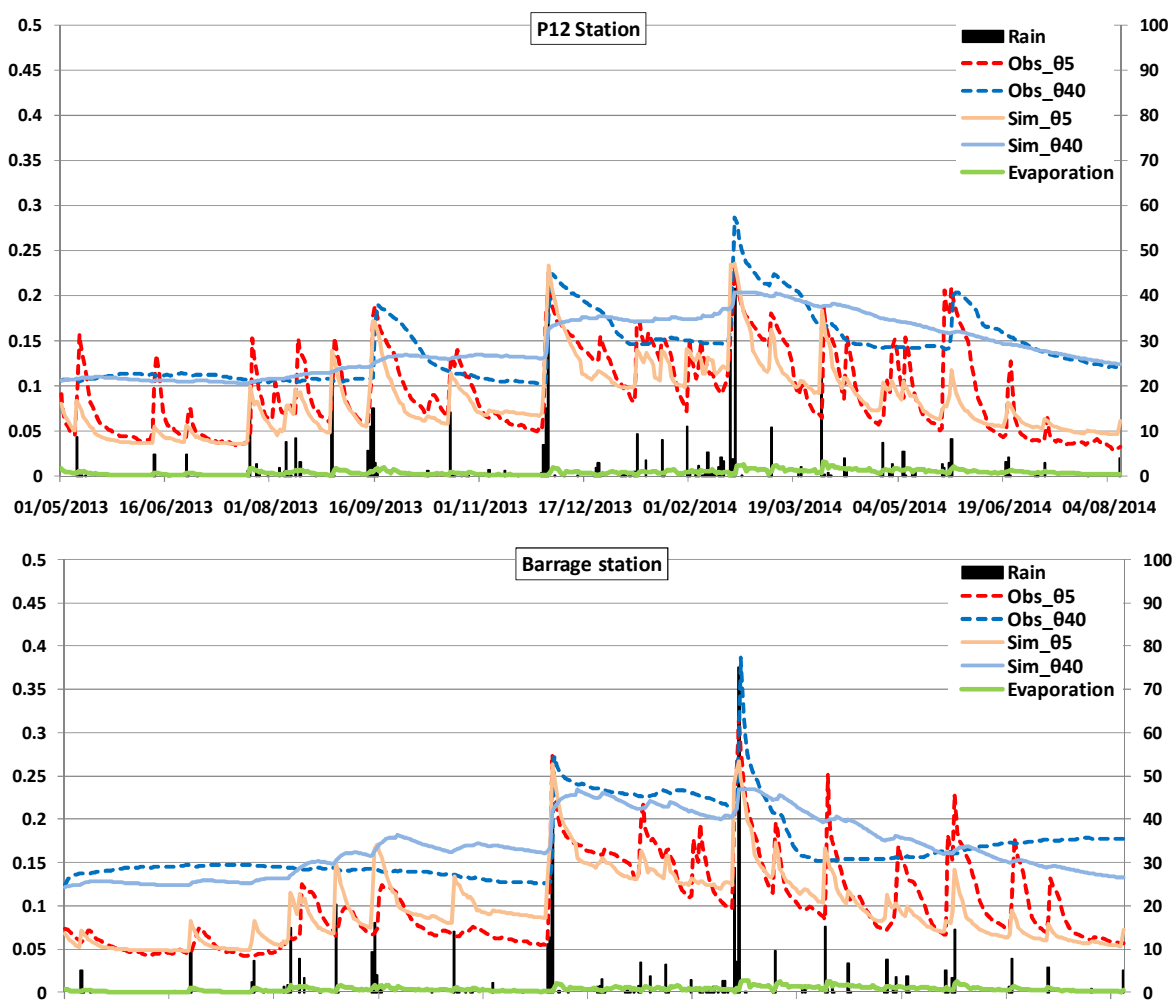

01/05/2013 16/06/2013 01/08/2013 16/09/2013 01/11/2013 17/12/2013 01/02/2014 19/03/2014 04/05/2014 19/06/2014 04/08/2014

Figure 10: Evaporation and soil moisture simulations using observed moisture measurements from (a) Chebika (b) P12 (c) Barrage. "Obs $\theta 5$ " and "Obs $\theta 40$ " correspond to the SM time series observed using continuous probes at depths of $5 \mathrm{~cm}$ and $40 \mathrm{~cm}$ respectively. "Sim $\theta 5$ " and "Sim $\theta 40$ " correspond to the volumetric water content simulated by the MHYSAN model, at depths of $5 \mathrm{~cm}$ and $40 \mathrm{~cm}$ respectively.

Table 3. Soil Parameters retained after calibrating MHYSAN with measured values of moisture. 


\begin{tabular}{|c|c|c|c|c|c|c|c|c|c|}
\hline $\begin{array}{c}\mathrm{Ze} \\
(\mathrm{mm})\end{array}$ & $\begin{array}{c}\mathrm{Zd} \\
(\mathrm{mm})\end{array}$ & $\begin{array}{l}\theta_{\mathrm{fc}} 5 \mathrm{~cm} \\
{\left[\mathrm{~m}^{3} \mathrm{~m}^{-3}\right]}\end{array}$ & $\begin{array}{l}\theta_{\text {res }} 5 \mathrm{~cm} \\
{\left[\mathrm{~m}^{3} \mathrm{~m}^{-3}\right]}\end{array}$ & $\begin{array}{c}\theta_{\mathrm{fc}} 40 \mathrm{~cm} \\
{\left[\mathrm{~m}^{3} \mathrm{~m}^{-3}\right]}\end{array}$ & $\begin{array}{l}\theta_{\text {res }} 40 \mathrm{~cm} \\
{\left[\mathrm{~m}^{3} \mathrm{~m}^{-3}\right]}\end{array}$ & $\begin{array}{c}\mathrm{R}_{\mathrm{E}} \\
{[\mathrm{mm}]}\end{array}$ & $\begin{array}{c}\text { cdif } \\
{\left[\mathrm{mm}^{2} \text { day }^{-1}\right]}\end{array}$ & $\mathrm{NASH}_{5 \mathrm{~cm}}$ & $\mathrm{NASH}_{40 \mathrm{~cm}}$ \\
\hline & \multicolumn{9}{|c|}{ Chebika station } \\
\hline \multirow[t]{2}{*}{194.5} & 500 & 0.37 & 0.04 & 0.27 & 0.1 & -5.57 & 6.23 & 81.2 & 26.2 \\
\hline & \multicolumn{9}{|c|}{ P12 station } \\
\hline \multirow[t]{2}{*}{188} & 866 & 0.24 & 0.03 & 0.2 & 0.09 & -21.7 & 3.47 & 66 & 63.2 \\
\hline & \multicolumn{9}{|c|}{ Hmidate station } \\
\hline \multirow[t]{2}{*}{225} & 500 & 0.1 & 0.03 & 0.11 & 0.06 & -25.1 & 0.31 & 62.4 & 50.8 \\
\hline & \multicolumn{9}{|c|}{ Barrage station } \\
\hline \multirow[t]{2}{*}{225} & 679 & 0.28 & 0.05 & 0.23 & 0.12 & -15.1 & 5.98 & 68 & 49 \\
\hline & \multicolumn{9}{|c|}{ Barrouta station } \\
\hline \multirow[t]{2}{*}{225} & 680 & 0.21 & 0.04 & 0.11 & 0.03 & -1.13 & 3.36 & 63 & 76.3 \\
\hline & \multicolumn{9}{|c|}{ Bouhajla station } \\
\hline \multirow[t]{2}{*}{225} & 280 & 0.16 & 0.01 & 0.11 & 0.01 & -10 & 3.05 & 58 & 39.1 \\
\hline & \multicolumn{9}{|c|}{ Sidi Heni station } \\
\hline 225 & 318 & 0.27 & 0.07 & 0.14 & 0.1 & -84.8 & 2.34 & 52 & 11 \\
\hline
\end{tabular}

Then, we propose a comparison of calibrated MHYSAN SM outputs at plot scale with in situ SM data and SAR moisture estimations. These comparisons take into account texture similarities, as well as the location between continuous probe stations and control plots for 2013-2014 season (only stations close to the control plots were used). In Fig. 11, we compare the MHYSAN surface SM at $5 \mathrm{~cm}$ depth with plot scale estimations made using: a) manual thetaprobe, and b) SAR moisture. In the last case, the $\mathrm{CSMN}_{3}$ used to calibrate the SAR moisture products, were removed from these comparisons. At plot scale, the results are characterized by a volumetric moisture bias and RMSE equal to 1.06 and $3.38 \%$ 390 respectively, when the MHYSAN SM simulations are compared to the SM manual thetaprobe 391 measurements. Similarly, the comparison between MHYSAN SM and SM SAR outputs leads to a 392 volumetric moisture bias and an RMSE equal to 0.63 and 6.11\%, respectively. Baghdadi et al., 2007 
compared SM SAR estimates over bare soils with SM ISBA simulations and obtained a mean difference between 0.4 and 10\% (RMSE $\leq 5 \%$ for 12 dates among the 18 examined dates and between $5 \%$ and $10 \%$ for the 6 remaining dates). The results are good indicators of the suitability of local SM datasets for the determination of soil moisture dynamics at the regional scale, on the basis of soil texture similarities.

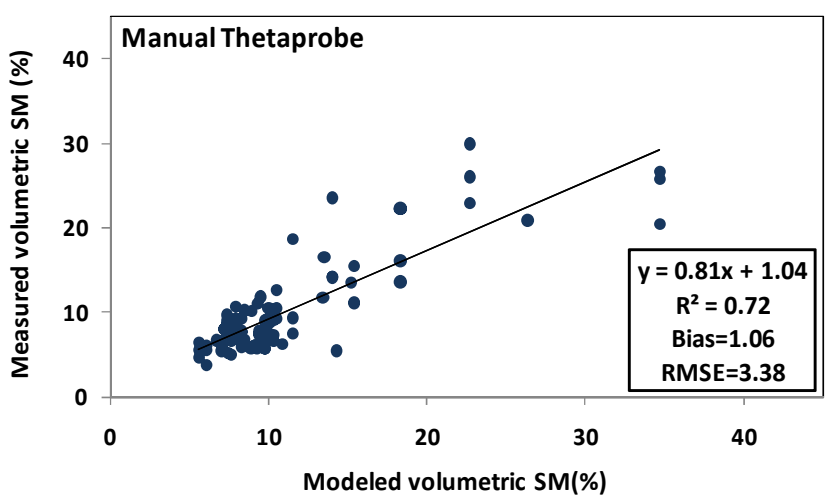

(a)

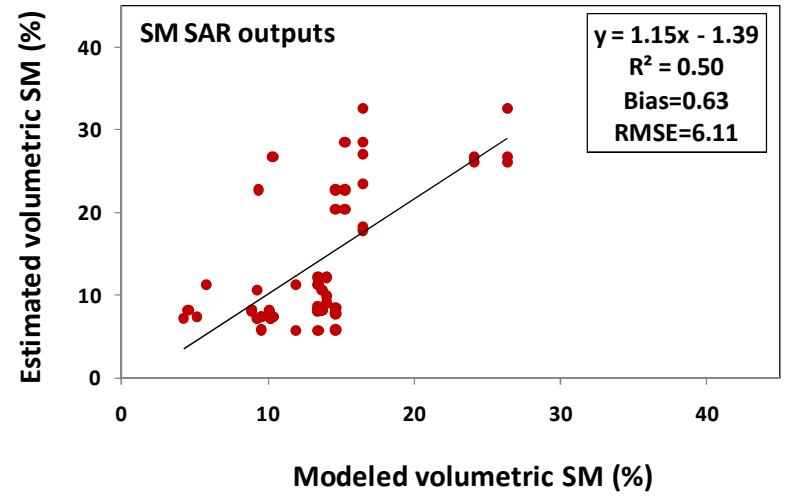

(b)

Figure 11: Comparisons from the 2013-2014 ground campaign, between Modeled volumetric SM values (5 cm depth) and: (a) SM Manual thetaprobe measurements and (b) SM SAR products, at plot scale.

\subsection{MHYSAN model calibration using satellite SM products}

In this section, the MHYSAN model was calibrated using SAR products only (from radar images acquired on seven different dates). As SAR SM estimates are related to the surface of the soil, the calibration was achieved only for this surface layer, although we computed performance criteria for both surface and deep layers. Following this calibration, the model was validated using daily SM observations derived from long-term data provided by the CSMN stations between 2013 and 2014. In the latter case, we used only those CSMN (4 stations) that were not used to calibrate the SAR moisture products. 
411 As no SAR SM estimations were available for the areas corresponding to the four CSMN stations used 412 to validate MHYSAN, the SAR SM corresponding to control plots with textures similar to that of each 413 respective station were used. Four different control-plot groups were thus selected, on the basis of the 414 Euclidean distance between their texture and that of their respective stations. Only distances of less than 41510 were retained. For each texture group, the relevant SAR SM value was computed as the mean of the 416 SM values determined for the corresponding control plots.

417 Fig. 12 shows the resulting estimated water balance variables, surface SM and evaporation, computed by the MHYSAN model using seven SAR SM products for the four different plots corresponding to each of the validation stations. The discrepancies between the estimated SM SAR products and the simulated SM MHYSAN outputs are presented in Table 4, showing that globally satisfactory 421 simulations are achieved. The use of just seven SAR SM estimations leads to good model performance. Brocca et al., 2008 reported the calibration of a conceptual model for soil water content balance, using a small number of isolated SM measurements. In this study, variations in RMSE and NASH values were determined as a function of the number of SM measurements (ranging from 3 to 15) used to calibrate the model. The results revealed that just seven SM measurements were sufficient to obtain good RMSE and NASH values, and to correctly calibrate the tested soil hydrological balance model.

We see on fig. 12 that although the seven satellite acquisition were achieved in a short time range as compared to the simulation length, the SAR moisture values vary considerably over time, due to important rainfall occurring during this period, which may have influenced positively our results.

Fig. 12 plots the calibrated MHYSAN SM outputs, together with the continuous thetaprobe SM observations. The Nash efficiency and statistical performance of these outputs are provided in Table 4. The validated version of the calibrated MHYSAN model is generally found to be in good agreement with the continuous probe observations and the MHYSAN simulations (Fig. 12 and Table 4). The performances shown in this table also indicate that there is a poor agreement between the simulations and observations in the case of the Sidi Heni and Hmidate stations. For the Sidi Heni station, this outcome can be explained mainly by the poorly representative rainfall data used for this station. Indeed, an 
437 increase in SM was measured in May without rainfall event recorded. For the Hmidate station, after the 438 important SM raise in December, a lower SM is observed compared to simulations. This result can be 439 related to the soil at the Hmidate station which has a very high percentage of sand (81\%), and just one 440 corresponding control plot (selected according to the distance between its texture and that of the 441 Hmidate station), which could lead to larger errors in the model.
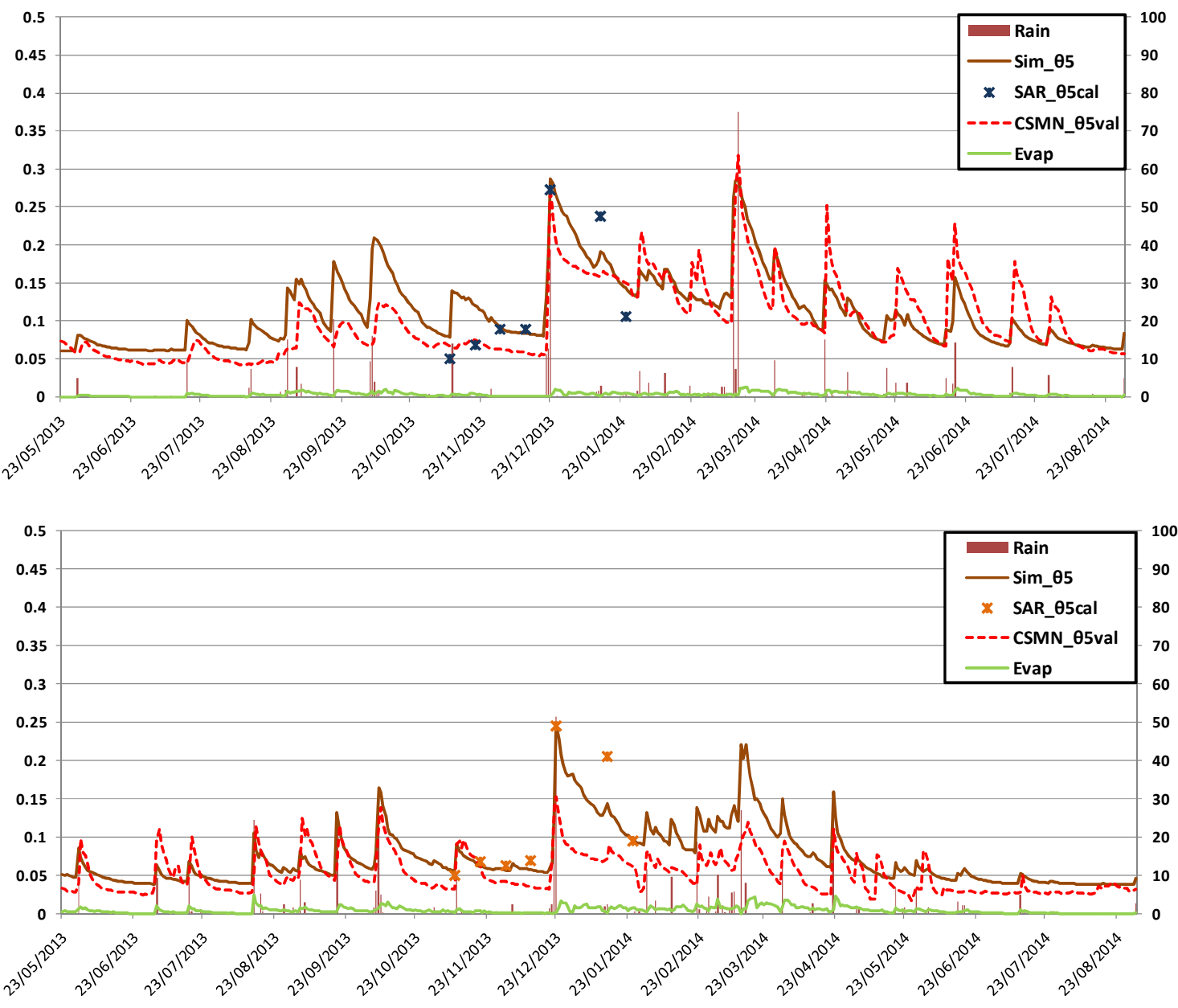

b) 


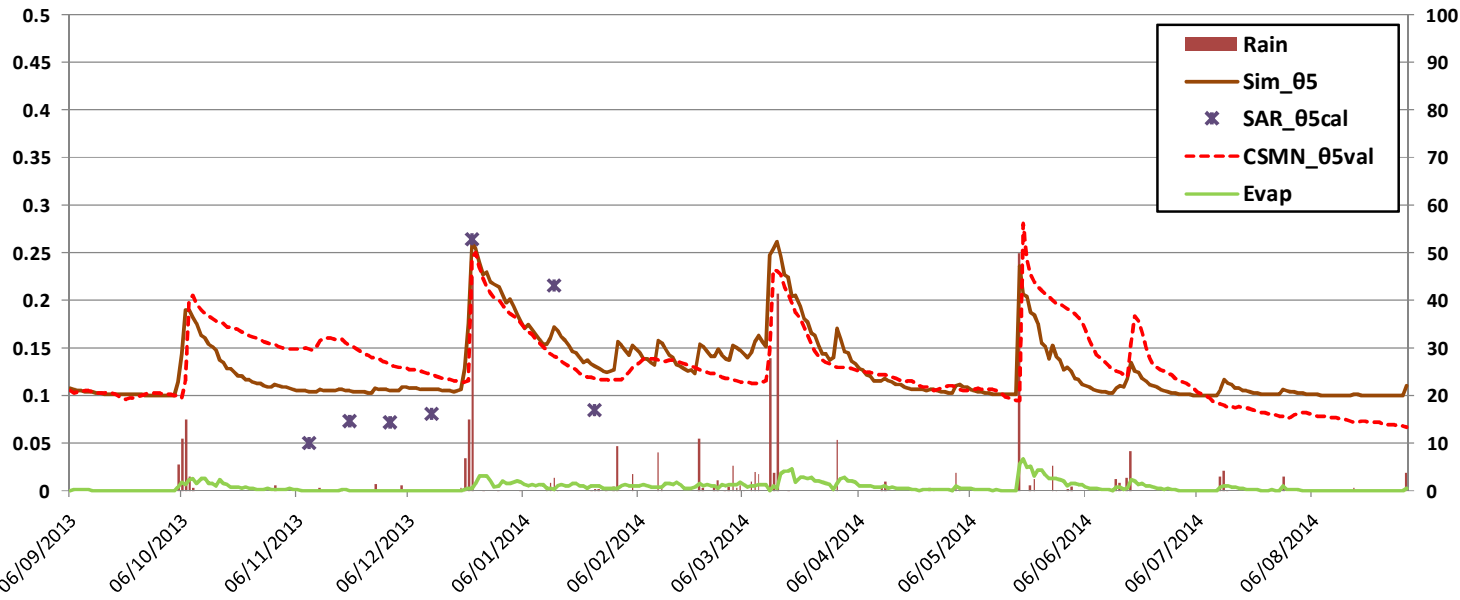

c)

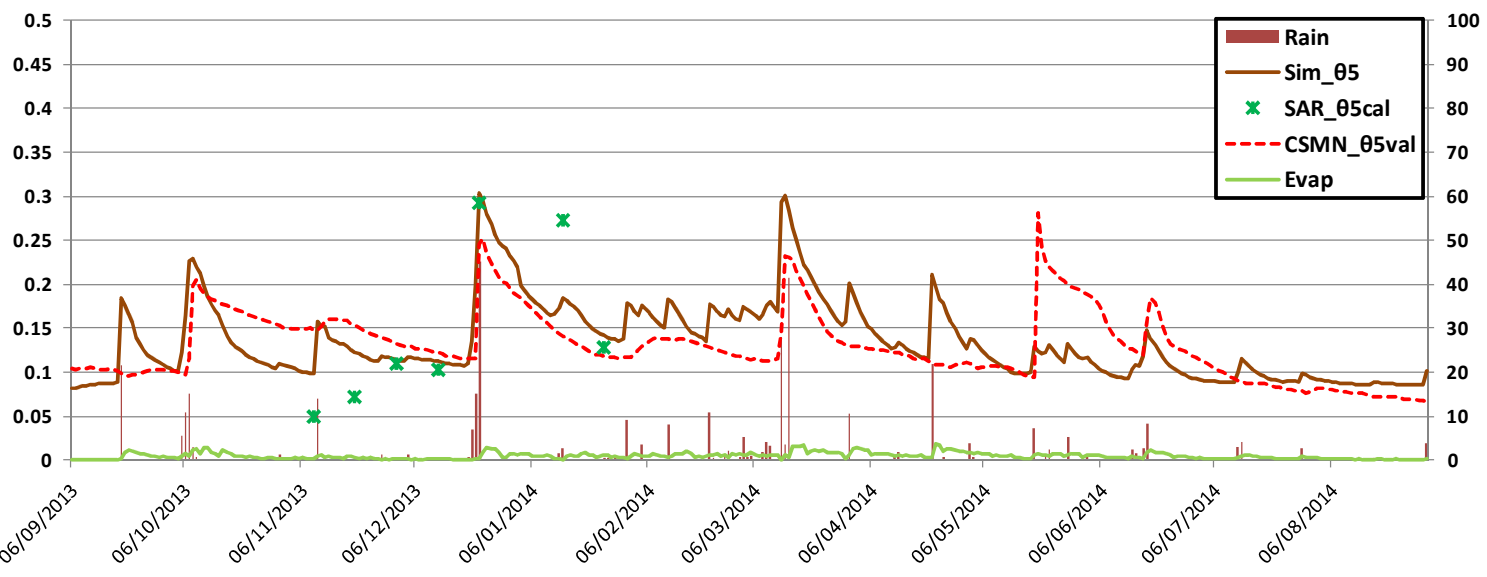

d)

Figure 12: Estimation of times series of water balance variables, using calibrated MHYSAN SAR data and validation results from different texture groups: (a) "Barrage" station; (b) "Hmidate" station; (c)

"Bouhajla" station and (d) "Sidi Heni" station

Table 4. Quality parameters of the MHYSAN "Calibration-Validation" process. The criteria for the calibration phase are computed only for the seven SAR dates. Validation criteria are computed for the full CSMN measurement period.

\begin{tabular}{|l|c|c|c|c|c|c|}
\hline \multirow{2}{*}{} & \multicolumn{2}{|c|}{ NASH (\%) } & \multicolumn{2}{c|}{ RMSE (\%) } & \multicolumn{2}{c|}{ Bias (\%) } \\
\cline { 2 - 7 } & CAL & VAL & CAL & VAL & CAL & VAL \\
\hline Barrage station & 87.6 & 57.5 & 2.84 & 3.16 & -0.43 & -0.18 \\
\hline Hmidate station & 89 & -88 & 2.4 & 3.4 & -1.06 & 2.23 \\
\hline Bouhajla station & 77 & 44.1 & 3.7 & 2.89 & 2.07 & -0.31 \\
\hline Sidi Heni station & 76.7 & 2.8 & 4.29 & 3.81 & 0.72 & 0.41 \\
\hline
\end{tabular}


453 Finally, the MHYSAN simulations using SAR SM products for calibration were compared with 454 MHYSAN outputs obtained using bibliographic FAO parameters only. The Ze and Zsol depth were 455 fixed respectively at 100 and $700 \mathrm{~mm}$ in order to fit with the SM probe depth. The soil resistance to 456 evaporation $R_{E}$ was determined using the REW values proposed by FAO for various soils textures 457 (table 19 of the FAO 56 paper), as well as the soil moisture values $\theta_{\text {res }}$ and $\theta_{\mathrm{fc}}$. Finally, the diffusion 458 coefficient was arbitrary fixed to the medium value of 2 as observed for several calibrations achieved in 459 previous studies (not shown here). The Nash efficiency and statistical performance of these simulations 460 are listed in Table 5, showing that the MHYSAN model performs better when SAR SM products are 461 used. These results confirm the effectiveness of TerraSAR-X SM retrieval for the calibration of a bare 462 soil hydrological model.

Table 5. Quality parameters of the MHYSAN model using FAO parameters only

\begin{tabular}{|l|c|c|c|}
\hline & NASH (\%) & RMSE (\%) & Bias (\%) \\
\hline Barrage station & -151 & 12.84 & 9.96 \\
\hline Hmidate station & -259 & 13.69 & 11.63 \\
\hline Bouhajla station & 70.2 & 4.22 & 1.42 \\
\hline Sidi Heni station & -423 & 20.36 & 18.31 \\
\hline
\end{tabular}

\section{Conclusions}

This study was designed to investigate the potential of high-resolution TerraSAR-X soil moisture (SM) products for the calibration of a soil water balance model. We used MHYSAN, a bare soil hydrological balance model, which simulates soil evaporation and moisture content over bare soil using as input meteorological data. The model was first calibrated using time series of daily SM continuously measured for some sites. The results had good NASH efficiencies ranged between 81.2 and $52 \%$ for $\mathrm{NASH}_{5 \mathrm{~cm}}$ and between 76.3 and $11 \%$ for $\mathrm{NASH}_{40 \mathrm{~cm}}$, thus showing that the MHYSAN model is able to correctly reproduce the SM. Validation of calibrated output SM was based on comparison over control plots with manual thetaprobe measurements and SM products obtained by SAR image processing.

473 These comparisons were made on the basis of texture similarities between continuous probes and control plots. The results have a bias of approximately 1.06 and 0.63 , and an RMSE equal to $3.38 \%$ and 
$4756.11 \%$, for the ground volumetric SM determined using manual thetaprobe and SAR moisture maps, 476 respectively.

477 The model was then calibrated using SAR SM maps retrieved on seven different dates ranging over two 478 months and was then validated using moisture data recorded at continuous probe stations during 15 479 months. We show that the model performs well with NASH efficiencies ranged between 76.7 and $89 \%$, 480 thus demonstrating that SAR data can actually be used to calibrate SM models without requiring 481 ground data. High agreement is observed between calibrated model and continuous thetaprobe 482 measurements. These results show that a simple SM model combined this SAR images acquired 483 for contrasted moisture condition may allow estimates of daily SM. An optimal use of this 484 approach could be achieved by using moisture data collected at different times of the year, during the 485 rainy season and the dry season, since the model's performance will necessarily vary for different types 486 of case study. The study presented here should be extended to other areas, in particular those 487 presenting other soil types (covered soils, degraded soils ...). Moreover, progress in the 488 parameterization of this model could benefit from a more varied range of SAR data.

489 The main limitation relies in the representatively of the meteorological forcing used. Indeed, if 490 rainfall data is not reliable, a frequent configuration in semi arid areas, then the model although 491 locally well calibrated will not be able to work correctly. In this case the solution would be to use 492 remote sensing not only to calibrate the model, but to monitor rainfall and the SM themselves. 493 This opportunity is about to be offered in the coming month thanks to the Sentinel-1 mission 494 which represent a considerable breakthrough providing frequent and free high resolution SAR 495 data all over the world. In future research, we plan to optimize and apply this approach to the case of 496 Sentinel1 SAR data, allowing moisture estimations to be made at a higher repeat rate, over longer 497 periods of time.

\section{Author Contributions}

499 Azza Gorrab and Vincent Simonneaux: data processing; data analysis and interpretation of results. 
500 Mehrez Zribi: SAR data analysis and interpretation of results.

501 Sameh Saadi: data processing.

502 Nicolas Baghdadi: SAR data analysis.

503 Zohra Lili-Chabaane: organization of experimental campaigns.

504 Pascal Fanise: site instrumentation.

\section{Acknowledgments}

506 This study was funded by the MISTRALS/SICMED, ANR AMETHYST (ANR-12 TMED-0006-01) and

507 TOSCA/CNES projects. We wish to thank all of the technical teams from the IRD and INAT (Institut National

508 Agronomique de Tunisie) for their consistent collaboration and support during the implementation of ground509 truth measurements. We are grateful for the financial support provided by the ANR/TRANSMED program for 510 the AMETHYST project (ANR-12-TMED-0006-01), as well as the mobility support provided by the PHC 511 Maghreb program ( $\mathrm{N}^{\circ}$ 32592VE). The authors wish to thank the German Space Agency (DLR) for kindly 512 providing them with TSX images under proposal HYD0007.

\section{References}

514 Albergel, C., Zakharova, E., Calvet, J. C., Zribi, M., Pardé, M., Wigneron, J. P., Novello, N., Kerr, Y., Mialon, 515 A., NouredDine Fritz. A first assessment of the SMOS data in southwestern France using in situ and airborne soil 516 moisture estimates: the CAROLS airborne campaign, Remote Sensing of Environment, 115, 2718-2728, 2011.

517 Allen, R.G.; Pereira, L.S.; Raes, D.; Smith, M. Crop Evapotranspiration-Guidelines for Computing Crop Water 518 Requirements; FAO Irrigation and Drainage Paper 56; FAO: Rome, Italy, p. 300, 1998.

519 Amri, R., Zribi, M., Chabaane, Z. L., Wagner, W., \& Hasenauer, S. Analysis of C-band scatterometer moisture 520 estimations derived over a semiarid region. Geoscience and Remote Sensing, IEEE Transactions on Geoscience 521 and Remote Sensing. 50(7), 2630-2638, 2012.

522 Aubert D., Loumagne C., Oudin L. et Le Hégarat-Mascle S., 2003. Assimilation of soil moisture into 523 hydrological models: the sequential method. Canadian journal of remote sensing, 29(6), 711-717.

Baghdadi N., Aubert M., Cerdan O., Franchistéguy L., Viel C., Martin E., Zribi M., Desprats J.F. Operational mapping of soil moisture using synthetic aperture radar data: application to the Touch Basin (France). Sensors Journal, vol. 7: 2458-2483, 2007. 
Baghdadi, N.; Cerdan, O.; Zribi, M.; Auzet, V.; Darboux, F.; Hajj, M.E.; Kheir, R.B. Operational performance of current synthetic aperture radar sensors in mapping soil surface characteristics in agricultural environments: Application to hydrological and erosion modelling. Hydrol. Proc. 22, 9-20, 2008.

Barrett, B.W.; Dwyer, E.; Padraig, W. Soil moisture retrieval from active space born microwave observations: An evaluation of current techniques. Remote Sens. 1, 210-242, 2009.

Bezerra, B.G.; dos Santos, C.A.C.; da Silva, B.B.; Perez-Marin, A.M.; Bezerra, M.V.C.; Bezerra, J.R.C.; Ramana Rao, T.V. Estimation of soil moisture in the root-zone from remote sensing data. Rev. Bras. Ciênc. Solo. 37, 596-603, 2013.

Brocca L, Melone F, Moramarco T. Empirical and conceptual approaches for soil moisture estimation in view of event-based rainfall-runoff modeling. In Progress in Surface and Subsurface Water Studies at the Plot and Small Basin Scale, Maraga F, Arattano M (eds). IHP-VI, Technical Documents in Hydrology No. 77. UNESCO: Paris; $1-8,2005$.

Brocca L., Melone F., Moramarco T., Wagner W., Naeimi V., Bartalis Z., Hasenauer S. Improving runoff prediction through the assimilation of the ASCAT soil moisture product. Hydrology and Earth System Sciences, 14(10):1881-1893, 2010.

Brocca, L., Melone, F., \& Moramarco, T. On the estimation of antecedent wetness conditions in rainfall-runoff modelling. Hydrological Processes, 22(5), 629-642, 2008.

Brocca, L., Moramarco, T., Melone, F., Wagner, W., Hasenauer, S., and Hahn, S.: Assimilation of surface and root-zone ASCAT soil moisture products into rainfall-runoff modelling,. IEEE T. Geosci. Remote, 50, 2542$2555,2012$.

Chen, X. and Hu, Q. Groundwater influences on soil moisture and surface evaporation. Journal of Hydrology, 297(1), 285-300, 2004.

Doubková, M.; van Dijk, A.I.J.M.; Sabel, D.; Wagner, W.; Blöschl, G. Evaluation of the predicted error of the soil moisture retrieval from C-band SAR by comparison against modeled soil moisture estimates over Australia. Remote Sens. Environ. 2012, 120(2), 188-196. doi: 10.1016/j.rse.2011.09.031

Draper, C., Mahfouf, J.-F., Calvet, J.-C., Martin, E., and Wagner, W., 2011. Assimilation of ASCAT near-surface soil moisture into the SIM hydrological model over France, Hydrol. Earth Syst. Sci., 15, 3829-3841,

doi:10.5194/hess-15-3829-2011.

Entekhabi D, Rodriguez-lturbe I. 1994. An analytic framework for the characterization of the space-time variability of soil moisture. Advances in Water Resources 17: 25-45.

Er-Raki, S.; Chehbouni, A.; Guemouria, N.; Duchemin, B.; Ezzahar, J.; Hadria, R. Combining fao-56 model and ground-based remote sensing to estimate water consumptions of wheat crops in a semi-arid region. Agric. Water Manag. 87, 41-54, 2007. 
Famiglietti, J. S., \& Wood, E. F. (1994). Multiscale modeling of spatially variable water and energy balance processes. Water Resources Research, 30(11), 3061-3078. DOI: 10.1029/94WR01498

Famiglietti, J. S., Rudnicki, J. W., \& Rodell, M. (1998). Variability in surface moisture content along a hillslope transect: Rattlesnake Hill, Texas. Journal of Hydrology, 210(1), 259-281. http://dx.doi.org/10.1016/S00221694(98)00187-5

François, C., Quesney, A., and Ottle, C.: Sequential assimilation of ERS-1 SAR data into a coupled land surfacehydrological model using an extended Kalman filter, Hydrometeorol., 4, 473-487, 2003.

Gorrab, A.; Zribi, M.; Baghdadi, N.; Mougenot, B.; Fanise, P.; Lili Chabaane, Z. Retrieval of Both Soil Moisture and Texture Using TerraSAR-X Images. Remote Sens., 7, 10098-10116, $2015 \mathrm{~b}$.

Gorrab, A.; Zribi, M.; Baghdadi, N.; Mougenot, B.; Lili Chabaane, Z. Potential of X-Band TerraSAR-X and COSMO-SkyMed SAR Data for the assessment of physical soil parameters. Remote Sens. 7, 747-766, $2015 \mathrm{a}$.

Gowda, P.; Chavez, J.; Colaizzi, P.; Evett, S.; Howell, T.; Tolk, J. ET mapping for agricultural water management: Present status and challenges. Irrig. Sci., 26, 223-237, 2008.

Iacobellis, V., Gioia, A., Milella, P., Satalino, G., Balenzano, A., \& Mattia, F. (2013). Inter-comparison of hydrological model simulations with time series of SAR-derived soil moisture maps. European Journal of Remote Sensing, 46(1), 739-757.

Koster, R.D.; Dirmeyer, P.A.; Guo, Z.; Bonan, G.; Chan, E.; Cox, P.; Gordon, C.T.; Kanae, S.; Kowalczyk, E.; Lawrence, D.; et al. Regions of strong coupling between soil moisture and precipitation. Science, 305, 11381140, 2004.

Li, Z.L.; Tang, R.L.; Wan, Z.M.; Bi, Y.Y.; Zhou, C.H.; Tang, B.H.; Yan, G.J.; Zhang, X.Y. A review of current methodologies for regional evapotranspiration estimation from remotely sensed data. Sensors, 9, 3801-3853, 2009.

Lievens, H., Tomer, S. K., Al Bitar, A., De Lannoy, G. J. M., Drusch, M., Dumedah, G., Hendricks Franssen, H.J., Kerr, Y. H., Martens, B., Pan, M., Roundy, J. K., Vereecken, H.,Walker, J. P., Wood, E. F., Verhoest, N. E. C. and Pauwels, V. R. N., 2015. SMOS soil moisture assimilation for improved hydrologic simulation in the Murray Darling Basin, Australia, Remote Sens. Environ., 168, 146-162.

López López, P., Wanders, N., Schellekens, J., Renzullo, L. J., Sutanudjaja, E. H., and Bierkens, M. F. P. (2016). Improved large-scale hydrological modelling through the assimilation of streamflow and downscaled satellite soil moisture observations. Hydrol. Earth Syst. Sci., 20(7), 3059-3076, doi: 10.5194/hess-20-3059-2016.

Manfreda S., Fiorentino M., Iacobellis V. (2005) - DREAM: a distributed model for runoff, evapotranspiration, and antecedent soil moisture simulation. Advanced Geosciences, 2: 31-39. doi: http://dx.doi.org/10.5194/adgeo2-31-2005. 
594 Matgen, P., Henry, J. B., Hoffmann, L. and Pfister, L., 2006. Assimilation of remotely sensed soil saturation 595 levels in conceptual rainfall-runoff models. IAHS-AISH publication, 226-234.

596 Pandey, V.; Pandey, P.K. Spatial and temporal variability of soil moisture. Int. J. Geosci., 1, 87-98, 2010.

597 Pathe, C.; Wagner, W.; Sabel, D.; Doubkova, M.; Basara, J.B. Using ENVISAT ASAR global mode data for 598 surface soil moisture retrieval over Oklahoma, USA. IEEE Trans. Geosci. Remote Sens., 47, 468-480, 2009.

599 Pauwels, V. R. N., Hoeben, R., Verhoest, N. E. C., De Troch, F. P. and Troch, P. A. (2002), Improvement of 600 TOPLATS-based discharge predictions through assimilation of ERS-based remotely sensed soil moisture values. 601 Hydrol. Process., 16: 995-1013. doi:10.1002/hyp.315

602 Pierdicca, N., Pulvirenti, L., Brocca, L., \& Fascetti, F. (2014). Multitemporal Soil Moisture Retrieval from Three603 Day Repeat ERS/SAR Data. Proceedings EUSAR 2014; 10th International European Conference on Synthetic 604 Aperture Radar; Berlin, 3-5 June 2014.

605 Qin, J., Liang, S., Yang, K., Kaihotsu, I., Liu, R. and Koike, T., 2009. Simultaneous estimation of both soil 606 moisture and model parameters using particle filtering method through the assimilation of microwave signal. 607 Journal of Geophysical Research: Atmospheres, 114(D15)

608 Renzullo, L. J., van Dijk, A. I. J. M., Perraud, J. M., Collins, D., Henderson, B., Jin, H., and McJannet, D. L.: 609 Continental satellite soil moisture data assimilation improves root-zone moisture analysis for water resources 610 assessment, J. Hydrol., 519, 2747- 2762, 2014.

611 Saadi, S.; Simonneaux, V.; Boulet, G.; Raimbault, B.; Mougenot, B.; Fanise, P.; Ayari, H.; Lili-Chabaane, Z. 612 Monitoring Irrigation Consumption Using High Resolution NDVI Image Time Series: Calibration and Validation 613 in the Kairouan Plain (Tunisia). Remote Sens. 7, 13005-13028, 2015.

614 Santi, E., Paloscia, S., Pettinato, S., Notarnicola, C., Pasolli, L., \& Pistocchi, A. (2013). Comparison between 615 SAR soil moisture estimates and hydrological model simulations over the Scrivia test site. Remote Sensing, 5(10), 616 4961-4976.

617 Seneviratne, S.I.; Corti, T.; Davin, E.L.; Hirschi, M.; Jaeger, E.B.; Lehner, I.; Orlowsky, B.; Teuling, A.J. 618 Investigating soil moisture-climate interactions in a changing climate: A review. Earth-Sci. Rev., 99, 125-161, 6192010.

620 Shabou, M; Mougenot, B.; Lili Chabaane, Z.; Walter, C.; Boulet, G.; Ben Aissa, N.; Zribi, M. 621 Soil clay content mapping using a time series of Landsat TM data in semi-arid lands. 622 Remote Sens., 7, 6059-6078, 2015. 
Simonneaux, V.; Duchemin, B.; Helson, D.; ErRaki, S.; Olioso, A.; Chehbouni, A. The use of high resolution image time series for crop classification and evapotranspiration estimate over an irrigated area in central morocco. Int. J. Remote Sens., 29, 95-116, 2008.

Simonneaux, V.; Lepage, M.; Helson, D.; Métral, J.; Thomas, S.; Duchemin, B.; Cherkaoui, M.; Kharrou, H.; Berjami, B., and Chebhouni, A. Estimation spatialisée de l'évapotranspiration des cultures irriguées par télédétection: Application à la gestion de l'irrigation dans la plaine du haouz (Marrakech, Morocco). Sécheresse, 20, 123-130, 2009.

Sutanto, S. J., Wenninger, J., Coenders-Gerrits, A. M. J., and Uhlenbrook, S.: Partitioning of evaporation into transpiration, soil evaporation and interception: a comparison between isotope measurements and a HYDRUS-1D model, Hydrol. Earth Syst. Sci., 16, 2605-2616, doi:10.5194/hess-16-2605-2012, 2012.

Tramblay, Y., Bouaicha, R., Brocca, L., Dorigo, W., Bouvier, C., Camici, S., \& Servat, E. Estimation of antecedent wetness conditions for flood modelling in northern Morocco. Hydrology and Earth System Sciences, 16(11), 4375-4386, 2012.

Wagner, W.; Pathe, C.; Doubkova, M.; Sabel, D.; Bartsch, A.; Hasenauer, S.; Blöschl, G.; Scipal, K.; MartínezFernández, J.; Löw, A. Temporal stability of soil moisture and radar backscatter observed by the Advanced Synthetic Aperture Radar (ASAR). Sensors, 8, 1174-1197, 2008.

Weisse A., Oudin L. et Loumagne C. Assimilation of soil moisture into hydrological models for flood forecasting: comparison of a conceptual rainfall-runoff model and a model with an explicit counterpart for soil moisture. Revue des sciences de l'Eau, Rev.Sci.Eau. 16/2, 173-197, 2003.

Zehe E, Bloschl G. Predictability of hydrologic response at the plot and catchment scales: role of initial condition. Water Resources Research 40: W10202. 2004.

Zhang, X., Zhang, X., Li, G. The effect of texture and irrigation on the soil moisture vertical-temporal variability in an urban artificial landscape: A case study of Olympic Forest Park in Beijing. Front. Environ. Sci. Eng., 9, 269-278, 2015.

Zribi, M.; Chahbi, A.; Shabou, M.; Lili-Chabaane, Z.; Duchemin, B.; Baghdadi, N.; Amri, R.; Chehbouni, A. Soil surface moisture estimation over a semi-arid region using Envisat ASAR radar data for soil evaporation evaluation. Hydrol. Earth Syst. Sci. 15, 345-358, 2011.

Zribi, M., Baghdadi, N., Holah, N., Fafin, O., and Guérin, C. Evaluation of a rough soil surface description with ASAR-ENVISAT Radar Data, Remote sensing of environment, Vol. 95, 67-76, 2005. 